الصدق العاملي للاختبارات المهارية المقترحة في اختيار الطلاب المتقدمين

للقبول في كلية التربية الرياضية جامعة الموصل

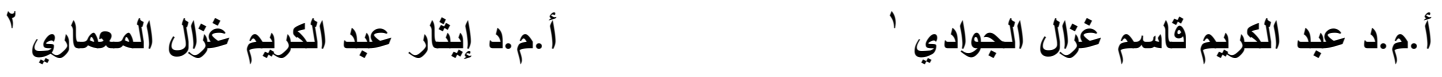

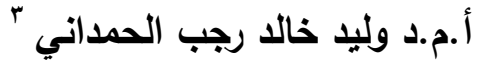

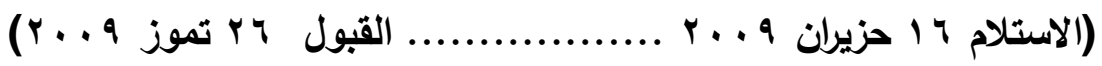

\title{
الملخص
}

إن القدرة على اختيار الأفراد المناسبين للنشاط الرياضي والألعاب على اختلاف أنواعها يأتي من خلال معرفة

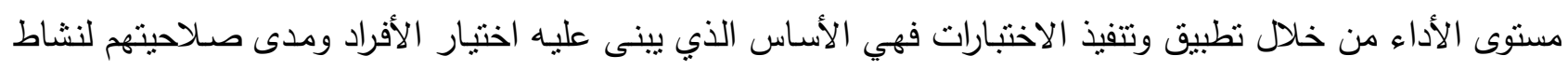

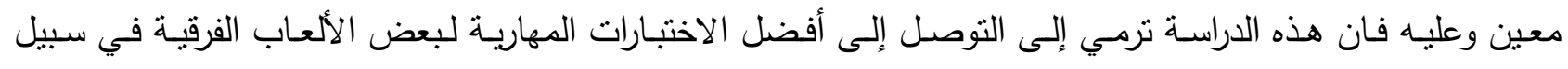

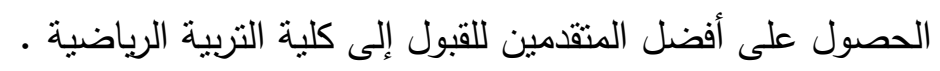
وقد هدفت الدراسة إلى ما يأتي :

- بناء بطاريات اختبار للألعاب (كرة السلة-كرة الطائرة-كرة القدم ) لطلاب المرحلة الأولى في كلية التربية الرياضية -

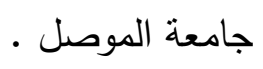

وقد تتاول الإطسار النظري مقدمـة عن أهميـة الاختبارات وتصنيفاتها والأسس العلمية للاختبار الجيد وبطاريـة الاختبار وأساليب قياس المهارات في الألعاب والتحليل ألعاملي وصدي الإن الإن اختبارات المهارات في الألعاب وأخيرا العوامل المؤثرة في

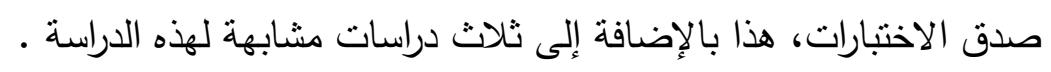

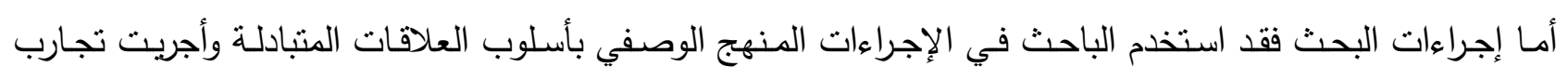
استطلاعية للحصول على الأوساط الحسابية والانحرافات المعيارية وصدق وثبات وموضوعية كل اختبار من الاختبارات

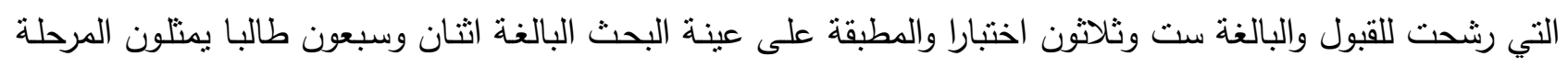

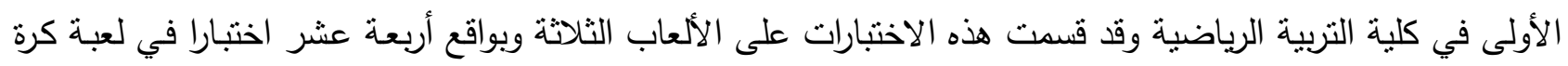

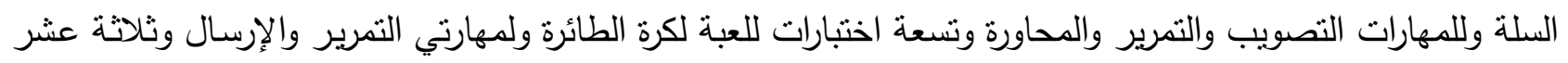

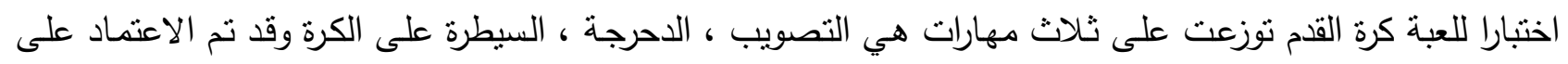

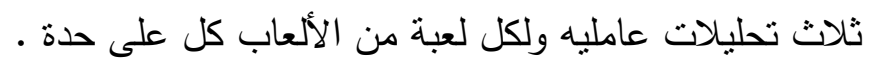

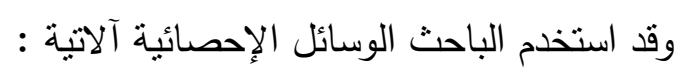

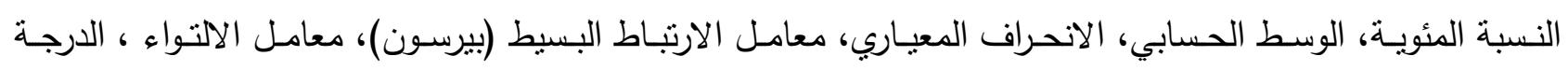

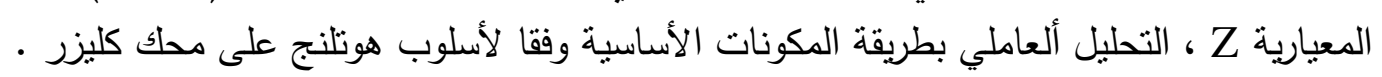

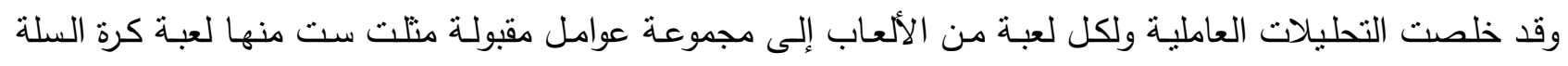

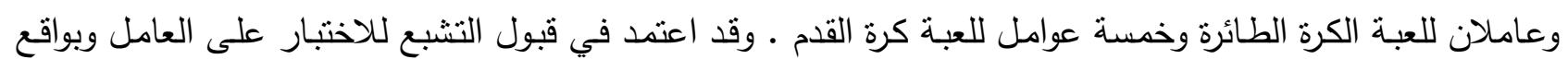
士. ·r وبعد عرض النتائج ومناقشتها وفقا لثروط قبول العامل نم التوصل إلى العوامل آلاتية مع مسمياتها :

' فرع الألعاب الفرقية/ كلية التربية الرياضية / جامعة الموصل / العرلق.

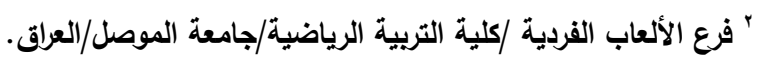

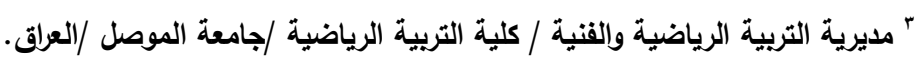




$$
\begin{aligned}
& \text { العامل الأول:دقة وسرعة التمرير والتصويب ورشح له اختبار (دقة التمرير على مستطيلات مسافة باته } 1 \text { م) }
\end{aligned}
$$

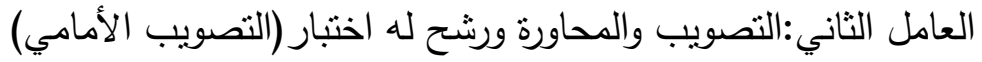

$$
\begin{aligned}
& \text { العامل الثالث:دقة وسرعة التمرير والمحاورة ورشح له اختبار (التمرير بيد واحدة من الأعلى على دوائر مسافة ه, ـ الم ) } \\
& \text { العامل الرابع:قدرة التتوع في استخدام المهارات ورشح لله اختبار (التمرير بالدفع ) }
\end{aligned}
$$

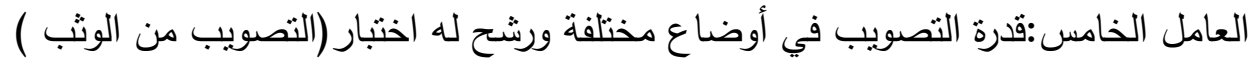

$$
\begin{aligned}
& \text { 7-العامل السادس: رشاقة المحاورة ودقة التصويب ورشح له اختبار (المحاورة بالكرة ذهابا وإيابا بين } 7 \text { شواخص الهن ) } \\
& \text { - لعبة كرة الطائرة } \\
& \text { العامل الأول:قدرة توصيل الكرة ورشح له اختبار (التمرير من الأعلى على الحائط ) } \\
& \text { ץ-العامل الثاني: دقة الإرسال والتمرير من الأعلى ومن الأسفل ورشح لهارئ اختبار (الإرسال من الأعلى ومن الألى الأسفل ) } \\
& \text { - لعبة كرة القدم } \\
& \text { العامل الأول:التحكم في استخدام الكرة ورشح له اختبار (السيطرة على الكرة خلال • ب ثانية ) }
\end{aligned}
$$

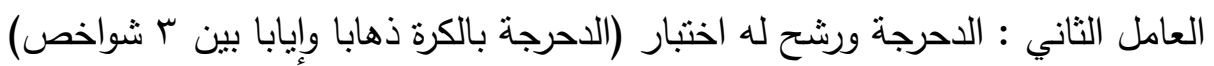

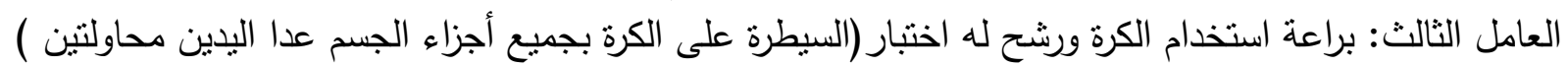

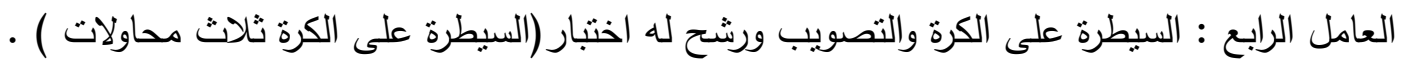

$$
\begin{aligned}
& \text { العامل الخامس: البراعة المهارية ورشح له اختبار (السيطرة على الكرة لأطول فترة ممكنة ) . }
\end{aligned}
$$

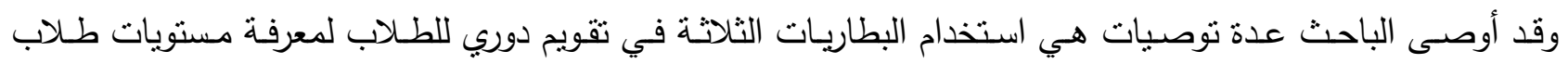

$$
\begin{aligned}
& \text { المرحلة الأولى بالإضـافة إلى الاسترشاد بالبطاريات المستخلصة كمؤشر للقبول في اختيار الطلاب ،كما اقترح الباحث } \\
& \text { إجراء دراسة كاملة للألعاب بالإضافة إلى الجانب البدني فضلا عن استخراج معايير للبطاريات الثلاثة . }
\end{aligned}
$$

\section{Design Certain Test Batteries of Certain Athletic Activities for the Students of the First Academic Year in College Of Physical Education, University of Mosul}

Asst. Prof. Dr. Abdul Kareem K. Al-Jawadi , Asst Prof. Dr. Ethar A. Ghazal Asst. Prof. Dr. Waleed K. Al-Hamdani

\section{ABSTRACT}

The ability to select individuals fit for sport activities is fulfilled conducting some tests to know the level of performances of these individuals. This study aims at reaching the best skill tests of some teams games in order to get the best candidates at the college of physical education it aims at:

_ Building test batteries of basketball, volleyball and soccer for the student of the first academic year in college of physical education .

The theoretical part implied the importance of tests, their classification the scientific bases of a good test, test batteries, method of athletic skills measurement, factorial Analysis , validity of athletic skills test, and factors influencing the validity of tests .

The description approach has been applied, Explorative tests have been conducted to get the means standard deviations, and the validity, reliability and objective of each test of the 36 teats applied on the sample of this research which consisted 72 first year student at the college of physical education. Theses tests have been divided in to three games: 14 tests for 
basketball, 9 for volleyball, 13 for football. Three factorial analysis have been conducted for each game. Statistical means have been used.

The factorial analysis for each game have been concluded some factors: 6 for basketball, 2 for volleyball, and 5 for football.

\section{1- التعريف بالبحث :

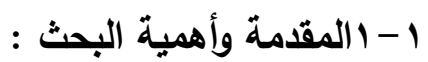

يكثنف لنا تطور القياس في التربية الرياضية انه كان يسير جنبا إلى جنب مع التقدم الذب حدث في أساليب

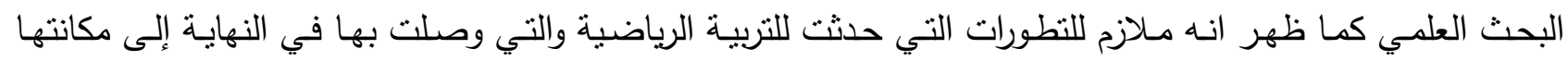

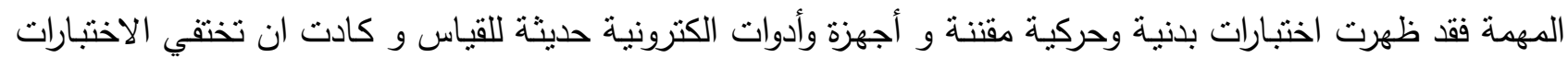

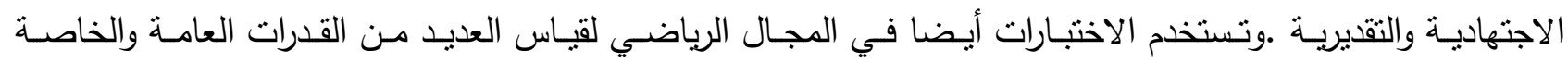

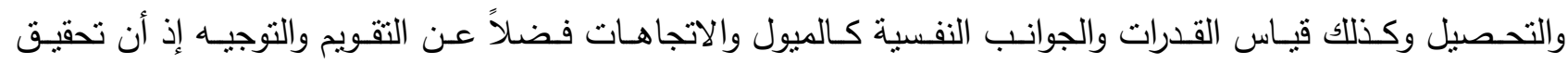

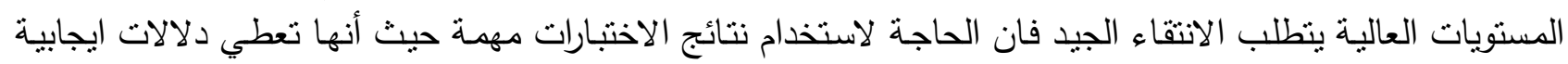

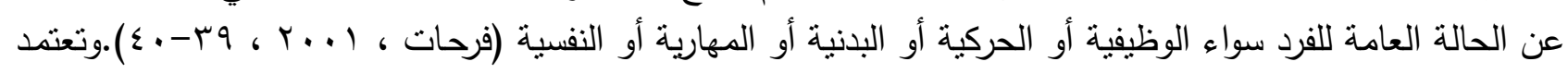

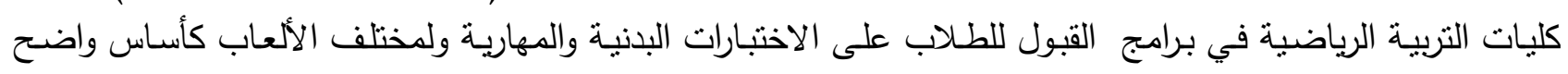

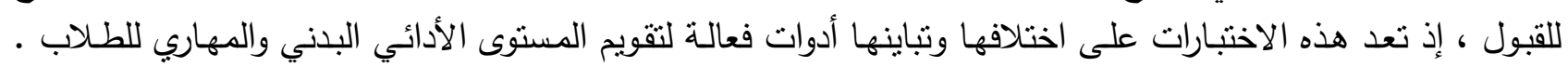

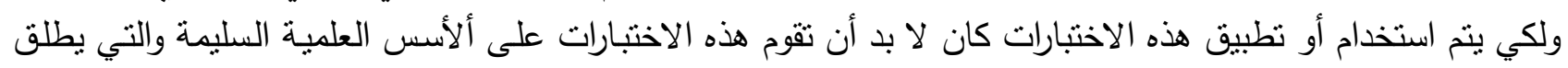

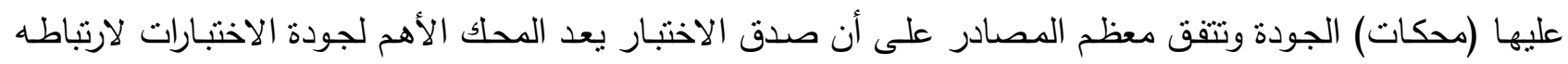

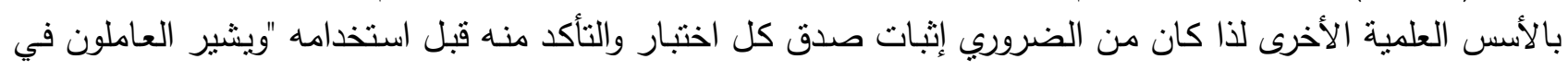

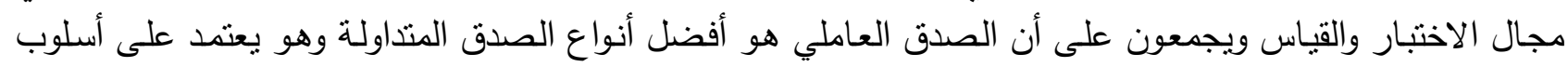

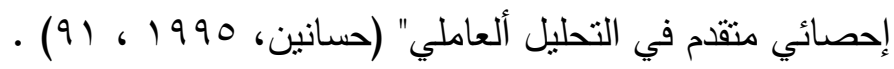

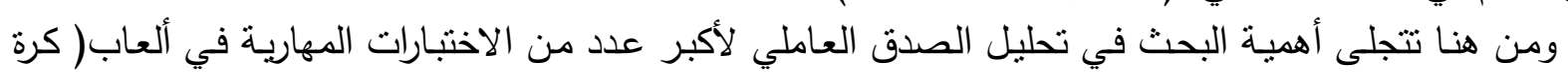

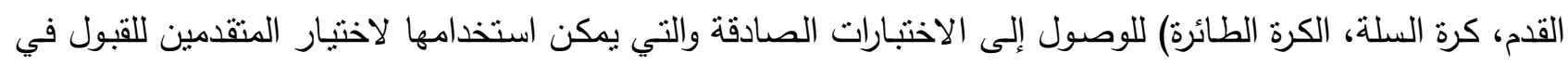
كليات التربية الرياضية.

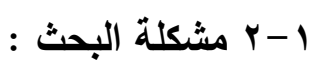

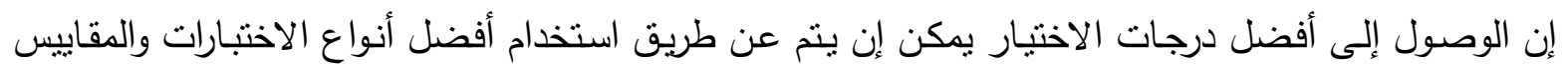

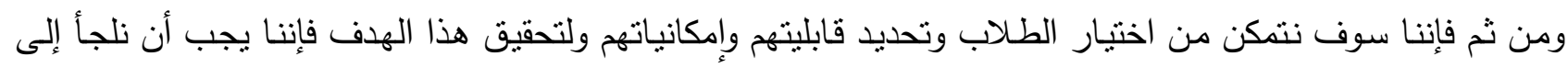

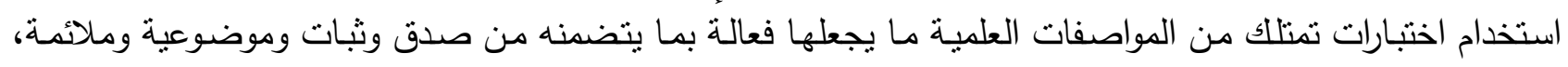

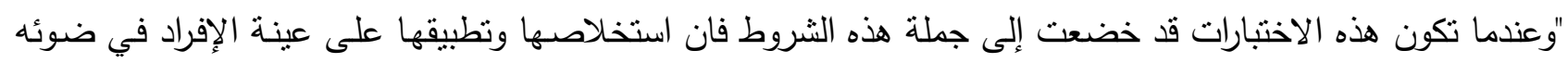

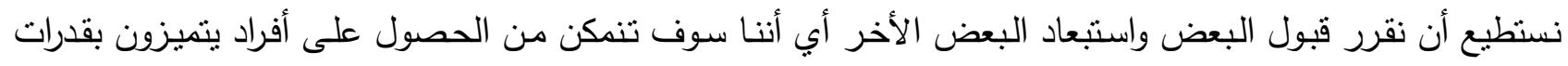

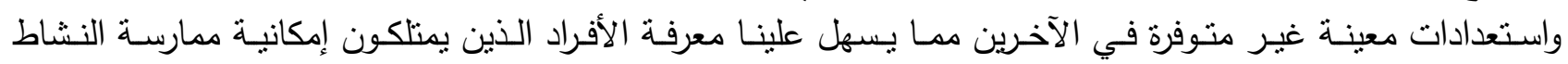

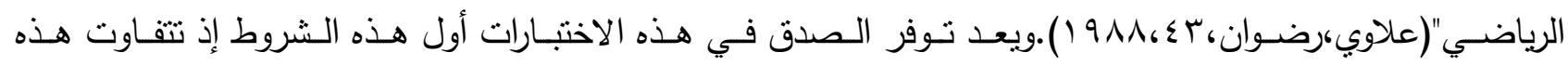

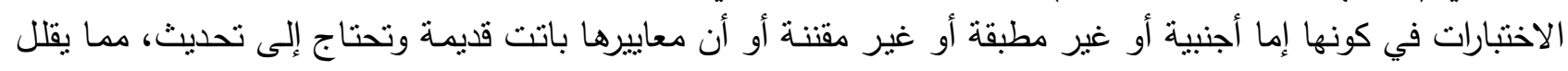

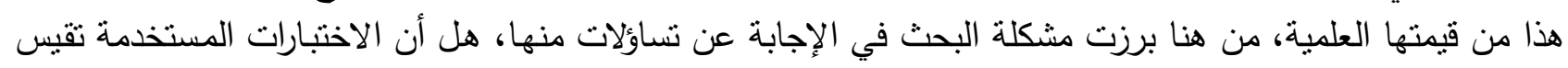

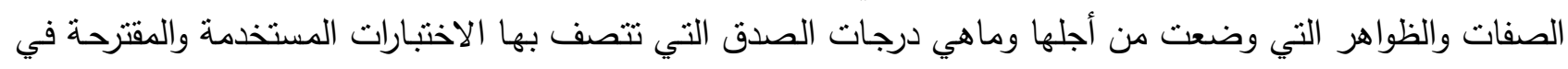
ألعاب( كرة القدم، كرة السلة، الكرة الطائرة).

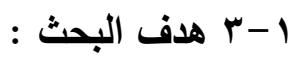

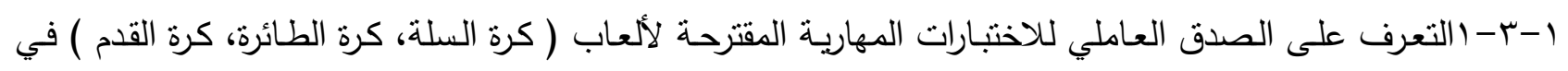

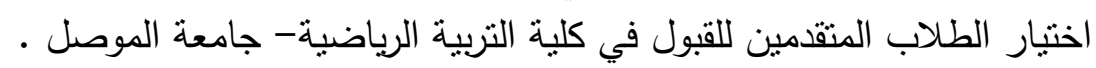




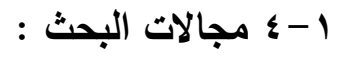

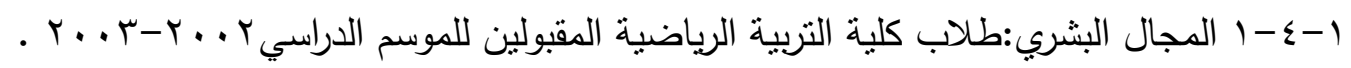

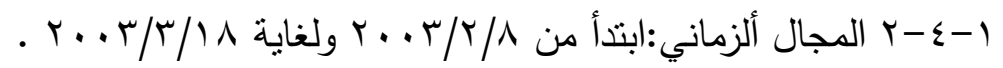

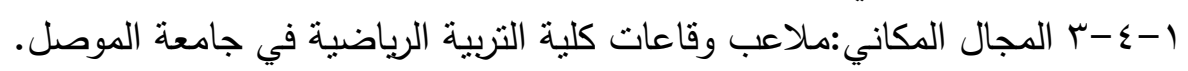

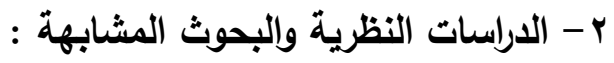

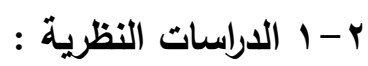

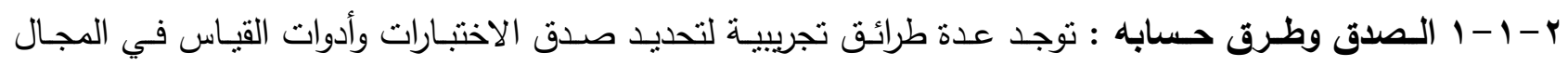

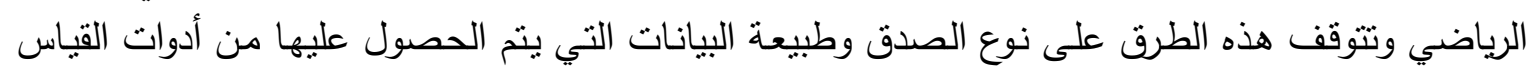

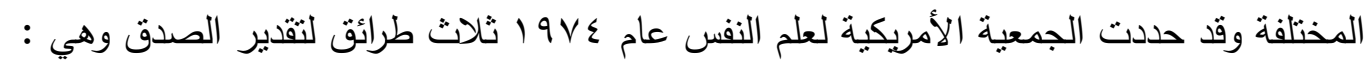

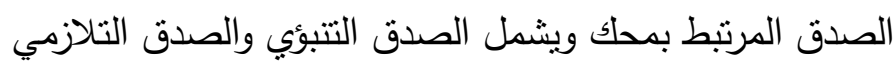
صدق المحتوى والمضمون صدق التكوين الفرضي وقد أعطي تقنيم آخر لأنواع الصدق وكالأتي: الصني:

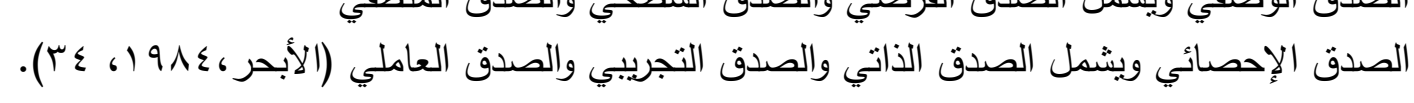

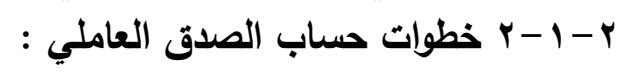

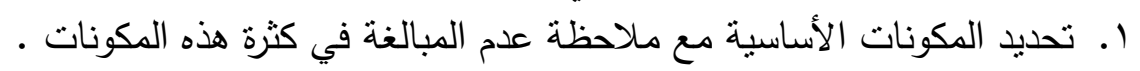

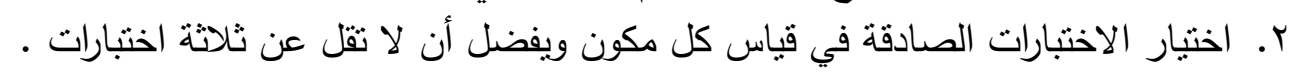

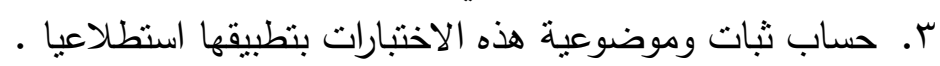

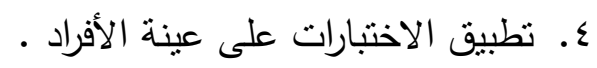

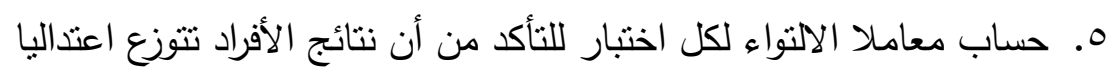

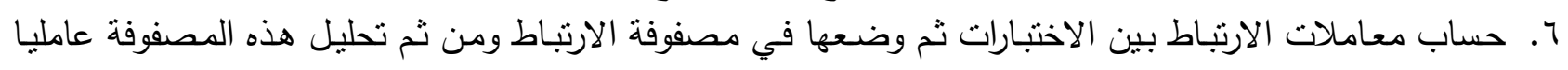

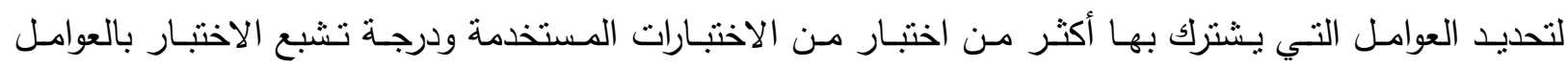

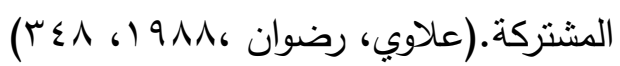

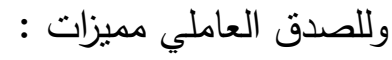

$$
\begin{aligned}
& \text { ا ـ بعد من أفضل أنواع الصدق. }
\end{aligned}
$$

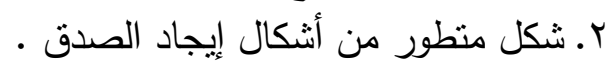

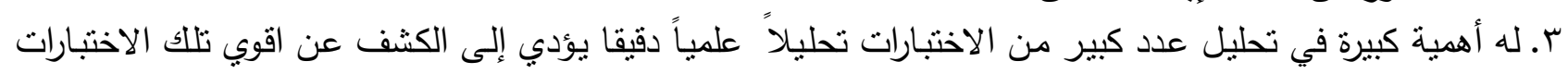

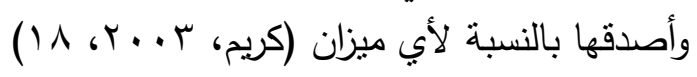

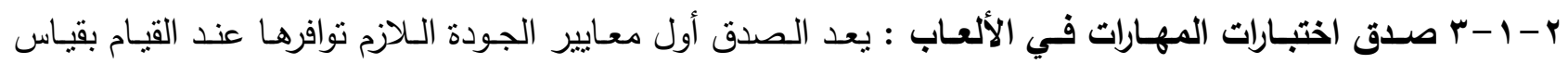

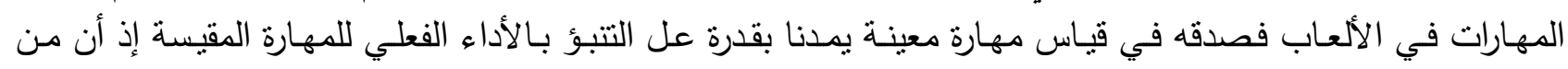

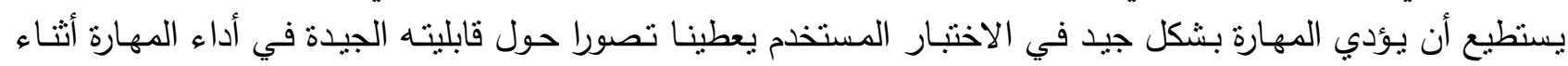

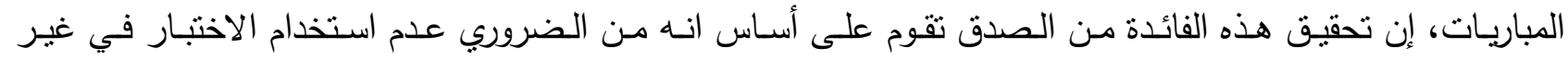

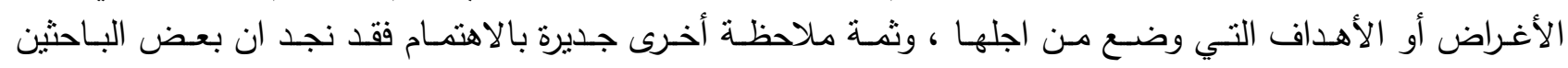

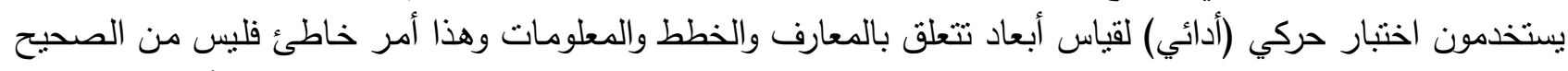

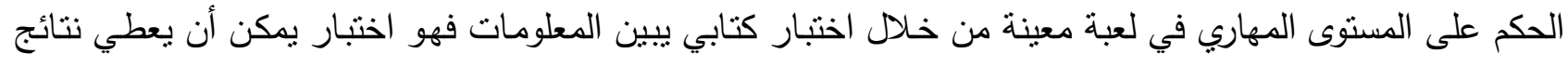

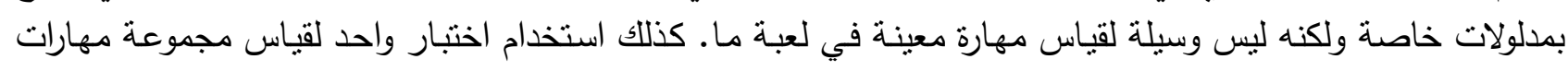

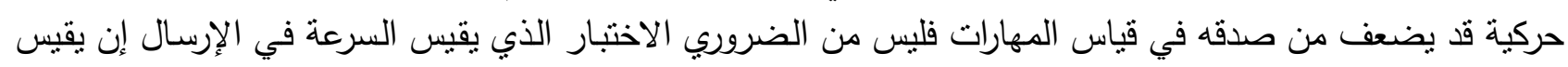

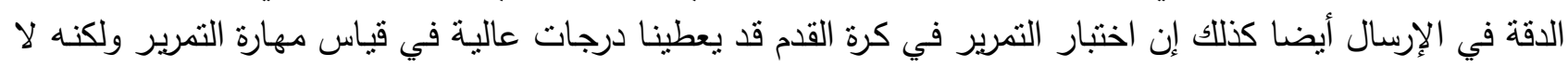




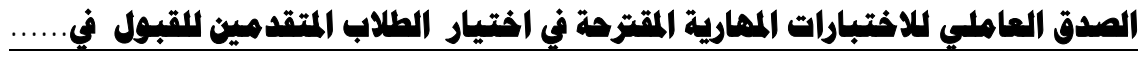

يجب ان يعد محك شمولي في القياس فهو محكوم بالموقف الأدائي الخاص الذي نشتقه منه هذا من ناحية ومن ناحية

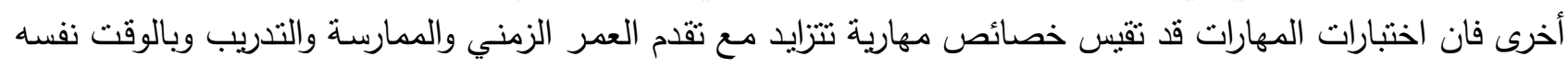

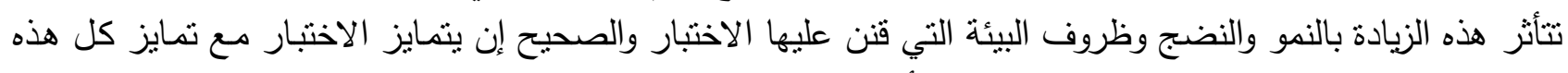

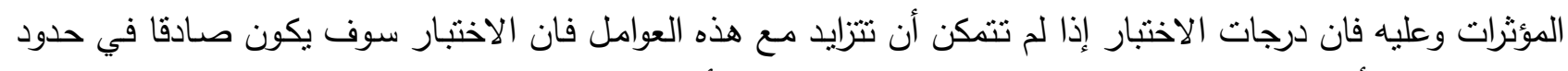

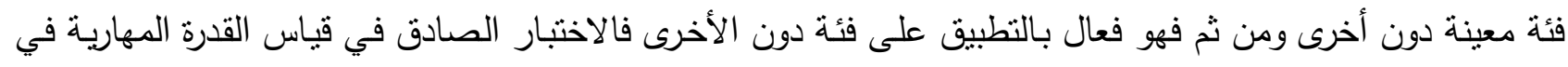

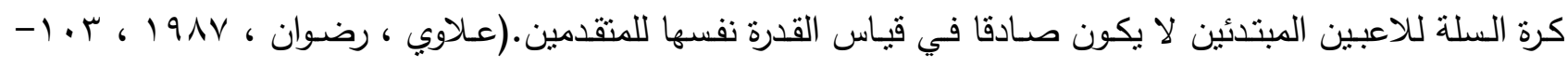

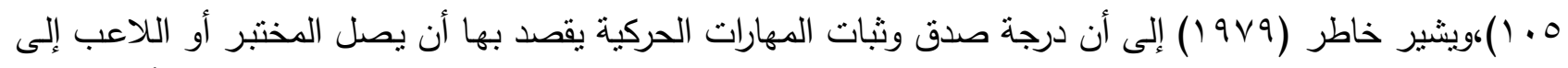

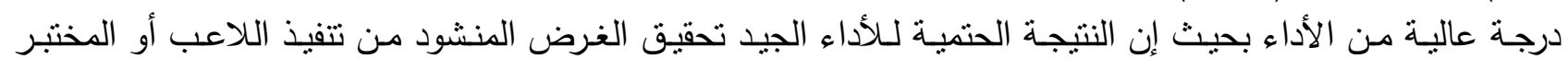

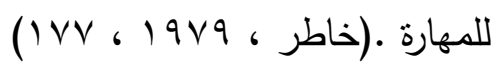
: r r الدراسات المشابهة

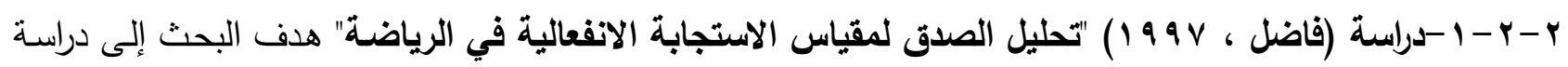

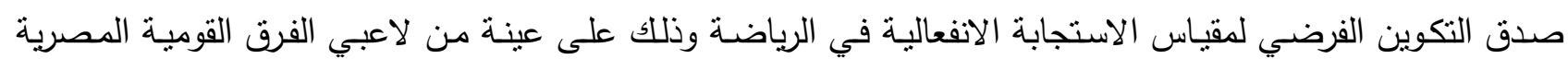

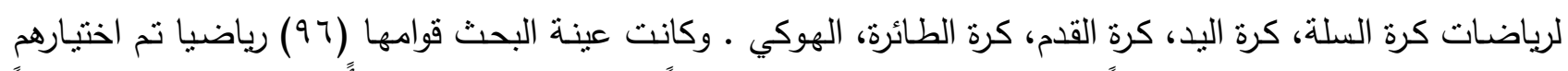

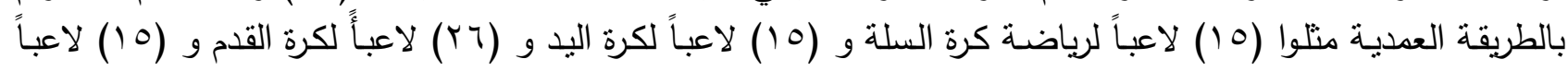

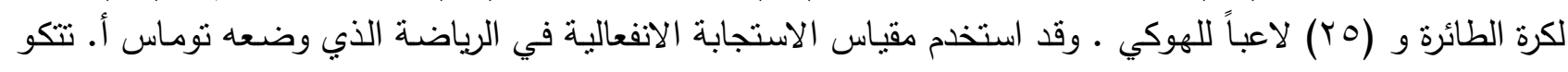

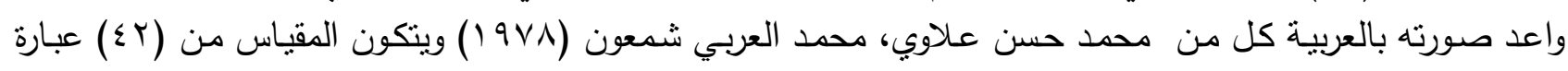

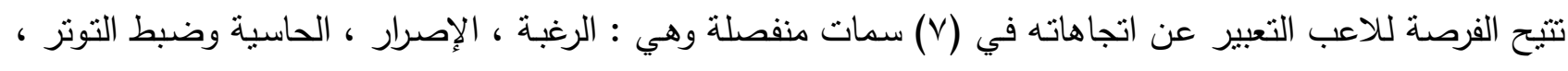

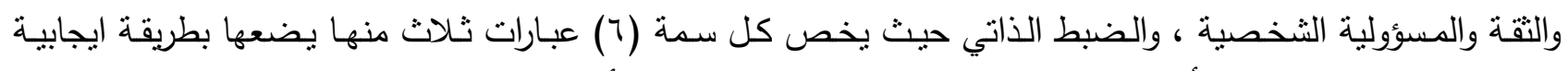
وثلاث بطريقة سلبية وقد تم أيجاد صدق المقياس إلى العربية بطريقين الأول باستخدام صدق المحتوى والثاني باستخدام

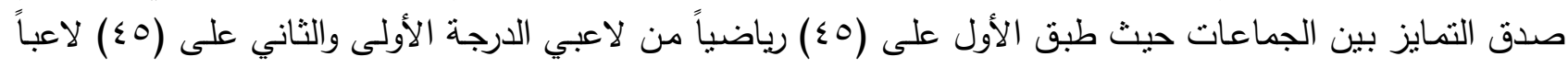

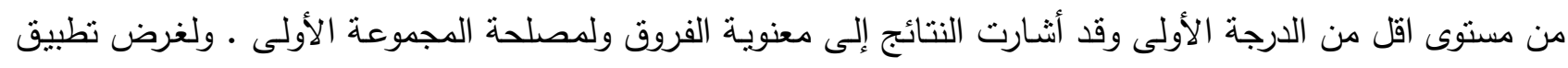

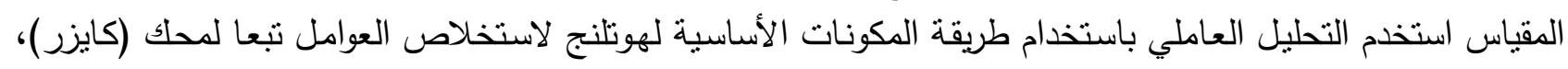

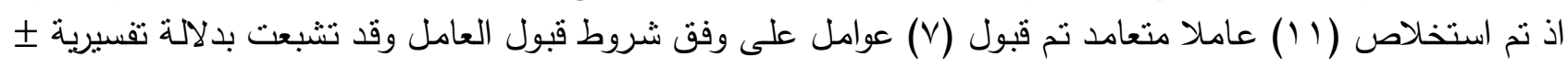

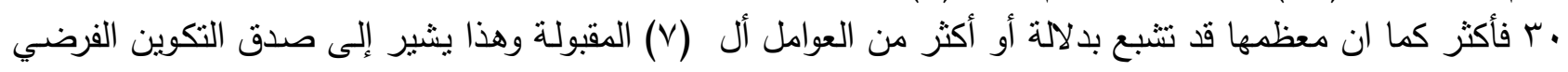

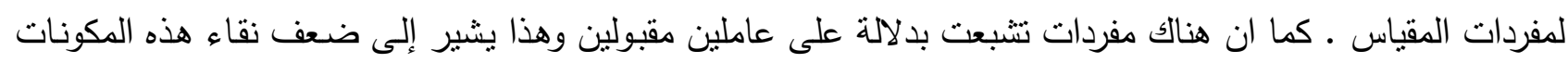

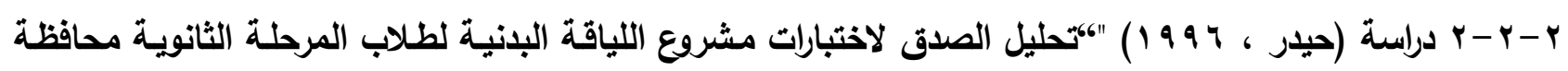

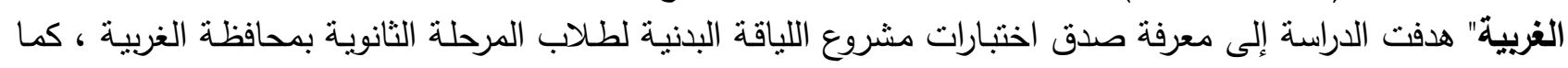

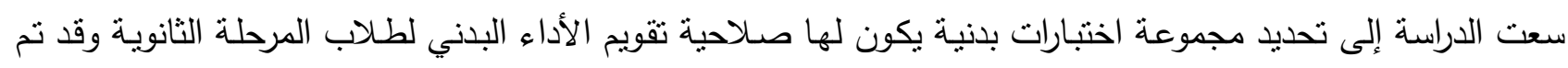

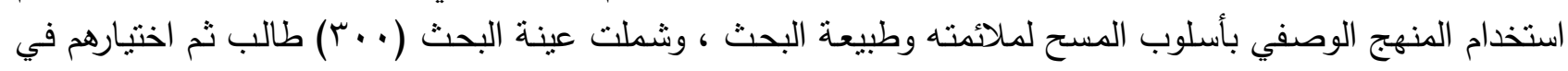

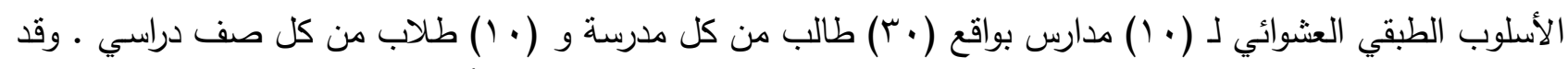

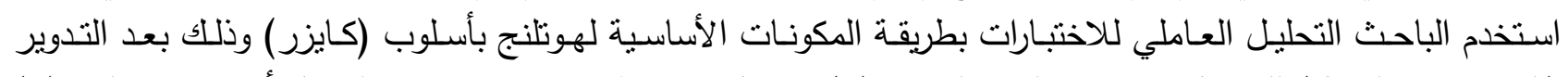

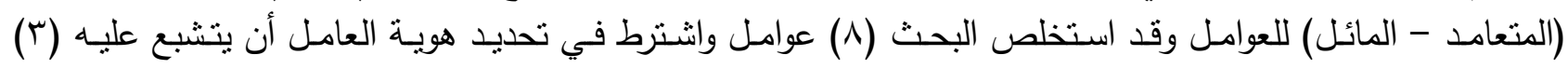

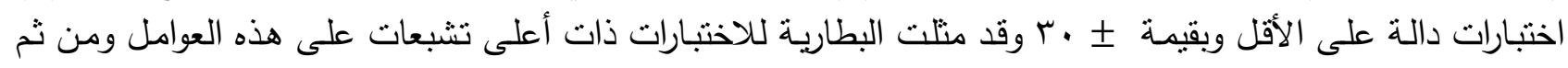

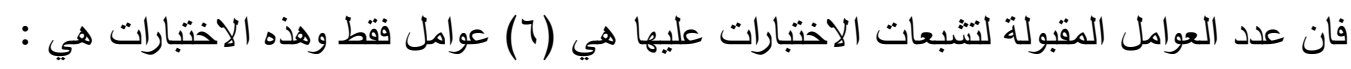

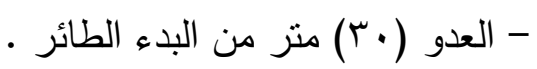
- ثي الذراعين من الانبطاح العميق المائل .

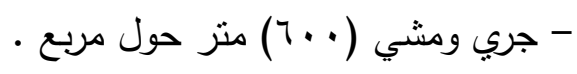
- الجلوس من الرقود في (•r) ثانية . 
- الجري المتعرج • - ثني الجذع للأمام من الوقوف ـ إن هذه الاختبارات قد تشبعت على عامل أو أكثر على العوامل أل (T) وهذا يشير إلى صحة ترشيح الاختبارات قيد البحث.

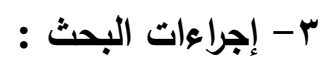

r- 1 منهج البحث :تم استخدام المنهج الوصفي بأسلوب دراسة العلاقات المنبادلة (المتداخلة) لملائمة وطبيعة البحث.

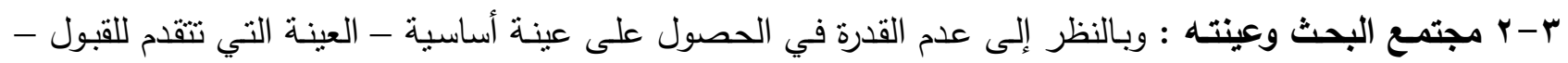
لذلك فأنه يمكن الاستعانة بالطلاب المقبولين للسنة الدراسية الأولى والذين لم يتعرضوا بعد لخبرات يمكن أن تكون مؤثرة

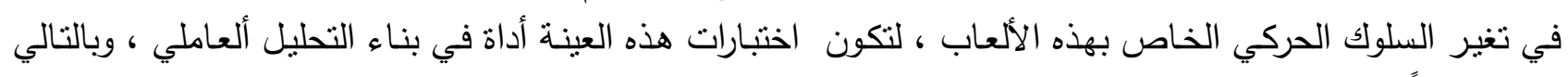

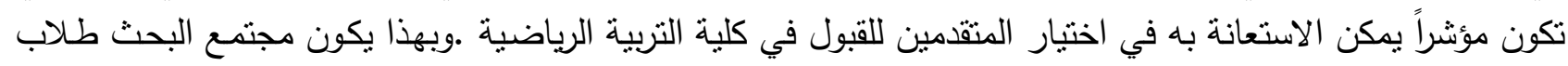

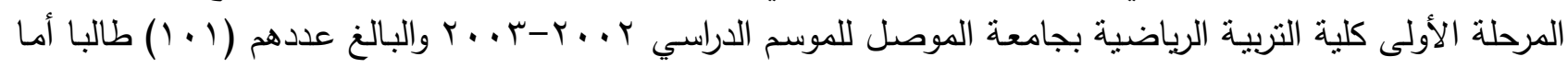

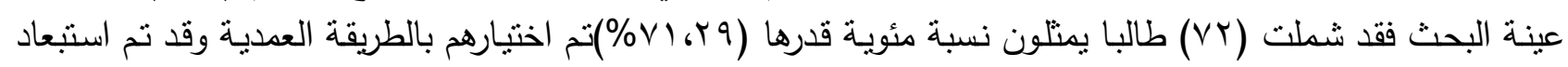

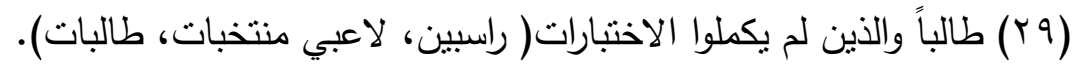

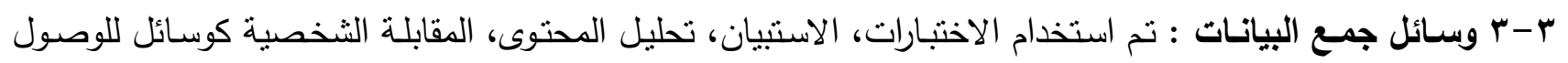
لبيانات البحث. ب- ع تحديد المهارات الأساسية للألعاب واختباراتها : من اجل تحديد المهارات الأساسية للألعاب الرياضية (كرة السلة،

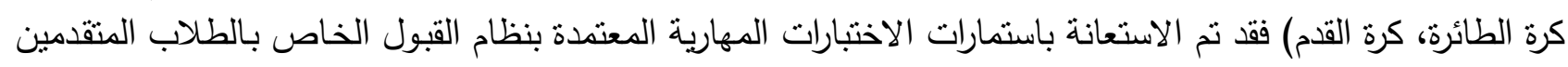
للقبول في كلية التربية الرياضية في القطر اذ تم تحديد المهارات الأساسية لهذه الألعاب وتم تحديد الاختبارات الخاصـة الأنة بها وهي: لعبة كرة السلة ثلاث مهارات واختباراتها (9 (1) اختبار وهي:-

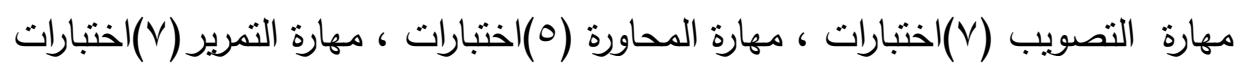

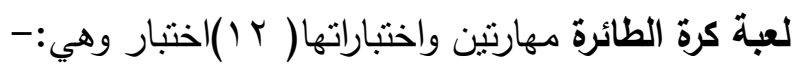

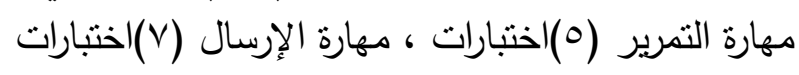

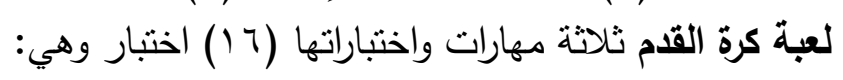

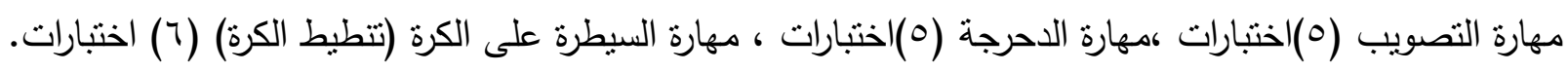

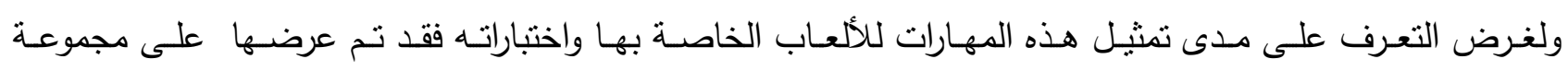
المختصين(ملحق (، Y) وبعد جمع استمارات الاستبيان تم حذف قسماً منها لعدم حصولها على نسب الاتفاق المطلوبة، وبذلك تصبح اختبارات لعبة كرة السلة (ع () اختبار ولعبة الطائرة (9)اختبارات ولعبة كرة القدم (ع () اختبار .

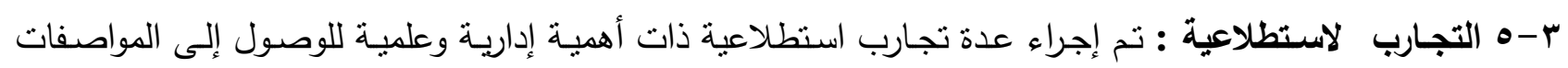
العلمية للاختبارات من صدق وثبات وموضوعية فضلا عن أهداف تتظيمية تتعلق بأسلوب تطبيق مجموعة الاختبارات

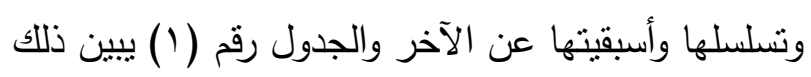

الجدول رقم (1) يبين الأوساط الحسابية والانحرافات المعيارية والمعاملات العلمية للاختبارات المرشحة للتحليل

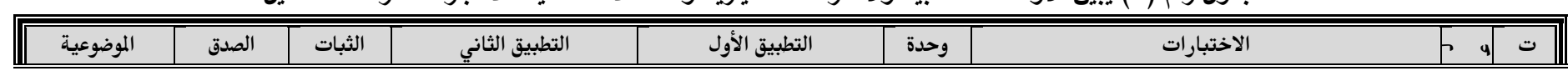




\begin{tabular}{|c|c|c|c|c|c|c|c|c|c|c|}
\hline & & & $\varepsilon \pm$ & 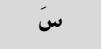 & $\varepsilon \pm$ & 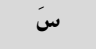 & & & & \\
\hline $1, \cdots$ & $\cdot, 9 \leqslant Y$ & $\cdot, \wedge \wedge 9$ & $\checkmark, \wedge Y V$ & $\Delta \wedge, V Y V$ & $\Lambda, \mu, r$ & $7 \cdot 9.9$ & 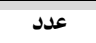 & | التمرير بالدفع & \multirow{14}{*}{$\mid \begin{array}{c}\mid \\
\vdots \\
0 \\
: 0 \\
: 3 \\
: 3\end{array}$} & .1 \\
\hline$\cdot, 99 \xi$ & - aro & $\cdot$, AVq & $r, v \cdots$ & $1 \cdot, 9 \cdot 9$ & $r, r .$. & $9, \cdot 9 \cdot$ & عدد & | دقة التمرير على مستطيلات Ylم & &.$r$ \\
\hline$\cdot, 999$ & $\cdot, 979$ & $\cdot, 9 \varepsilon \cdot$ & $1,1 \cdot 0$ & $9,1 \cdot 9$ & $1,+71$ & ᄉ,90. & ثا & التمرير إلى حائط & & $r$ \\
\hline $1, \cdots$ & $\cdot, १ \leqslant V$ & $\cdot, \wedge 91$ & r,VYM & $18, Y V Y$ & 1,9६. & 19,111 & 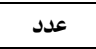 & حائط الارتداد & &.$\varepsilon$ \\
\hline$\cdot, 997$ & $\cdot, \Lambda \mathrm{Y}$ & $\cdot, \mathrm{V} \mathrm{VA}$ & $r, 9 \wedge 1$ & rr,Tr & r, rYT & $r r, \cdot \cdot$ & 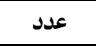 & التمرير بيد واحدة من أعلى على دوائر مسافة ه,· ا متر & & .0 \\
\hline$\cdot, 99 \mathrm{~V}$ & $\cdot, 909$ & $\cdot, 94$. & $1, r \cdot 0$ & $17, r 9 q$ & $1, \varepsilon \mu r$ & $1 Y, \leqslant 00$ & ثا & المحاورة بالكرة بين ؛ شواخص & & .7 \\
\hline •,११ץ & $\cdot, 9$ Yro & $\cdot, \wedge O \mathrm{~V}$ & $1, r \cdot 1$ & $1 \%, r \Delta q$ & $1, \varepsilon \vee \varepsilon$ & $|r, 00|$ & ثا & |المحاورة بالكرة بين ץ شواخص منتهية|التصويب & &.$v$ \\
\hline$\cdot, 99 \mathrm{~V}$ & $\cdot, 911$ & •,974 & Y,9TV & $\wedge, \wedge \%$ & $r, \Sigma q r$ & $\Lambda,\{\otimes\}$ & ثا & المحاورة بالكرة بين ؟ شواخص & &.$\wedge$ \\
\hline$\cdot, 90 \mathrm{~V}$ & •,arl & $\cdot$ •, ^TV & $\cdot, \pi \xi \varepsilon$ & $0, \lambda \vee 1$ & $\cdot, \varepsilon \wedge \mu$ & $0, \wedge T \varepsilon$ & ثا & |المحاورة بالكرة بخط مستقيم حول شاخص واحد & & .9 \\
\hline$\cdot, १ 9 ६$ & $\cdot, \Lambda \varepsilon$ & •,vir & $0, \cdot Y r$ & $\varepsilon 9,1 \pi \mu$ & $\{, 01$. & $0 ., 7 \cdot 9$ & معيارية & | التصويب من الوثب & & .1 . \\
\hline $1, \cdots$ & $\cdot, १ \leqslant \vee$ & $\cdot, \wedge 91$ & $\varepsilon, \wedge Y Y$ & 19, r & $0,10 \varepsilon$ & $|\wedge,| \wedge \mid$ & عدد & التصويب من اسفل السلة لمدة ·r ثانية & & .11 \\
\hline$\cdot, 991$ & $\cdot, 9 \leqslant \wedge$ & $\cdot, 9 \cdots$ & $r, r 00$ & IV, $\cdots$ & $r, \cdots r$ & $19, \mathrm{rVY}$ & 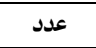 & التصويب الامامي & & .14 \\
\hline $1, \cdots$ & $\cdot, 900$ & $\cdot, 91 \%$ & $r, q r_{0}$ & $1 \%, 9 \cdot 9$ & $r, \xi \cdots$ & $|r,| \Lambda \mid$ & 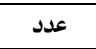 & التصويب الجانبي & & .11 \\
\hline $1, \cdots$ & •, QRr & $\cdot, \wedge v \cdot$ & $r, 1+1$ & $1 \cdot, r V Y$ & r,qus & Q,YVY & 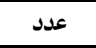 & الرمية الحرة & & $.1 \varepsilon$ \\
\hline $1, \cdots$ & $\cdot, 9 \vee \varepsilon$ & $\cdot, 90$ & 18,YAr & \&1, & $18, \cdot 0 Y$ & $\varepsilon \cdot, q \cdot q$ & ع عدد & | التمرير من الأعلى على حائط & \multirow{9}{*}{ - } & .1 \\
\hline$\cdot, 994$ & $\cdot, 971$ & - aro & IY,AV. & 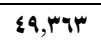 & 1., ror & $\sum V, q \cdot q$ & 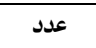 & التمرير على حلقة كرة السلة & &.$r$ \\
\hline$\cdot, 900$ & $\cdot, 900$ & $\cdot, 914$ & 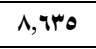 & 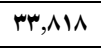 & 11, Vos & $\mathrm{MT}, 1 \wedge 1$ & 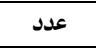 & التمرير من الاسفل على حائط & & $r$ \\
\hline$\cdot, 9 \vee 4$ & $\cdot, 9 \leqslant 1$ & $\cdot, \wedge \mathrm{T}$ & $14, \cdot 1$ & $\Delta V, \Delta \leqslant \theta$ & 11, AYq & $\Delta Q, r q \mu$ & 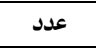 & التمرير من الأعلى بالاصابع ومن الاسفل بالذراعين & &.$\varepsilon$ \\
\hline $1, \cdots$ & $\cdot, 9 \cdot 1$ & •, גוr & $\Lambda, \cdot 10$ & 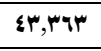 & $\Lambda, \otimes \vee 1$ & $\{r, \otimes \leqslant \theta$ & 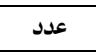 & الارسال من الأعلى أو من الاسفل & & .0 \\
\hline$\cdot, 9 \leq \varepsilon$ & $\cdot, 99 \cdot$ & $\cdot 9 \mathrm{rm}$ & $\varepsilon, \vee \backslash 1$ & $r q, \cdots$ & 0,09 . & $r \varepsilon, q m q$ & 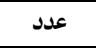 & الارسال من الأعلى ومن الاسفل & & .9 \\
\hline $1, \cdots$ & $\cdot, 911$ & $\cdot$ •, & 9,210 & $\mathrm{ra,| \Lambda |}$ & 7,9m & 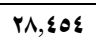 & 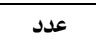 & الارسال & &.$v$ \\
\hline $1, \cdots$ & $\cdot, 9 \vee 0$ & •,90r & $1 \varepsilon, \cdot \varepsilon r$ & $\varepsilon Y, V Y V$ & $10,7 V \wedge$ & $\varepsilon I, r V Y$ & 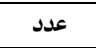 & الارسال الطويل & &.$\wedge$ \\
\hline $1, \cdots$ & $\cdot, 9 Y \varepsilon$ & $\cdot, \wedge$, \& & $9, Y \wedge 0$ & $T \cdot, V Y V$ & $\wedge, \varepsilon \wedge \vee$ & $\Delta ৭,\{\otimes \varepsilon$ & 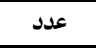 & الارسال للنقاط الصعبة & & .9 \\
\hline$\cdot, 9 \leqslant \vee$ & $\cdot, 919$ & $\cdot, \wedge \leqslant 0$ & $\varepsilon, \vee \vee \uparrow$ & $\Pi 1, \mathrm{YVY}$ & $\varepsilon, \wedge \wedge \vee$ & $71,9 \cdot 9$ & 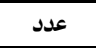 & | التصويب على المستطيلات الاربعة & \multirow{14}{*}{ 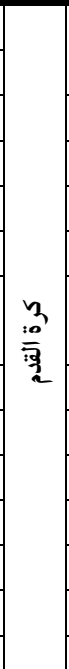 } & .1 \\
\hline $1, \cdots$ & $\cdot, 9 \leqslant V$ & $\cdot, \wedge 9 \vee$ & $1, \cdot \mathrm{rq}$ & 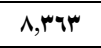 & $\cdot, \lambda \cdot 9$ & ᄉ, Im & 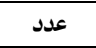 & دقة التصويب على مرمى & &.$r$ \\
\hline$\cdot, 9 \wedge 9$ & $\cdot, 911$ & $\cdot, 97 \pi$ & $r, \wedge \varepsilon 1$ & $10,\{0\{$ & $r, 7+\cdots$ & $|\varepsilon, \wedge| \wedge$ & 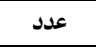 & التصويب القريب على ثلاثة دوائر مسافة Y ا متر & & $r$ \\
\hline $1, \cdots$ & $\cdot, 9 Y \wedge$ & • • ATr & $1,7 \mu \varepsilon$ & $9,\{0\}$ & $1, r 91$ & 9,m Mrm & 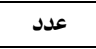 & التصويب على هدف قدم بداخله هدف كرة يد & &.$\varepsilon$ \\
\hline$\cdot, 990$ & $\cdot, \wedge 99$ & $\cdot, \wedge \cdot \varepsilon$ & 9,00Y & $r \cdot, q q$ & $1 \cdot, \pi r r$ & rA,rqu & 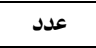 & |السيطرة على الكرة لمدة ·ب ثانية & & .0 \\
\hline $1, \cdots$ & $\cdot, 91$. & - ,97r & Q,rVV & IN,rqV & $\Lambda, \wedge \cdot \wedge$ & $1 \wedge,\{07$ & ثا & السيطرة على الكرة لاطول فترة ممكنة داخل دائرة & & .7 \\
\hline $1, \cdots$ & •, qur & $\cdot, \wedge v \cdot$ & $v$, Yor & ro, $\cdots$ & A,YYq & $r \mid, \Delta \leqslant \theta$ & 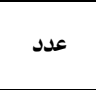 & 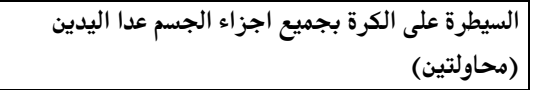 & &.$v$ \\
\hline $1, \cdots$ & $\cdot, 999$ & •,१९४ & 19,AOr & MI,INI & $r \cdot, v \mp 1$ & ra,rar & 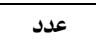 & السيطرة على الكرة (ثلاث) محاولات & &.$\wedge$ \\
\hline $1, \cdots$ & $\cdot, 99 \mathrm{~V}$ & $\cdot, \mathrm{quV}$ & $1 \xi, 0$. & Ve,rVY & IY,AYY & VE,Trq & 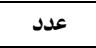 & السيطرة على الكرة خلال دقيقة واحدة & & .9 \\
\hline $1, \cdots$ & $\cdot, \mathrm{VIN}$ & $\cdot, 0.9$ & $1 Y, \cdot 0 \cdot$ & ra,VYY & $1 \varepsilon, V r q$ & rV,qu & 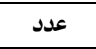 & | السيطرة على الكرة (•ه) فما فوق & & .1. \\
\hline$\cdot, 979$ & $\cdot, \wedge \varepsilon$ & $\cdot$, VAr & $\cdot, 9 \wedge \cdot$ & $1 \varepsilon, Y \otimes \varepsilon$ & $\cdot, 991$ & $\mid \&, \& \wedge \Lambda$ & ثا & |الدحرجة بالكرة ذهابا وايابا بين ه شواخص & & .11 \\
\hline$\cdot, 9 \vee 9$ & $\cdot, 909$ & $\cdot, 910$ & 1,911 & $|\varepsilon, \mu| \varepsilon$ & $1, v \uparrow$ & IE,VYV & ثا & الدحرجة بالكرة ذهابا وايابا بين r شواخص & & $.1 Y$ \\
\hline$\cdot, 99 \mathrm{~V}$ & $\cdot, 9$, & 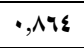 & 1,Var & $1 \varepsilon, \cdot Y \varepsilon$ & $1, \pi+1$ & $\mid V, \varepsilon \Psi \cdot$ & ثا & الدحرجة بالكرة ذهابا وايابا بين ^ شواخص & & .14 \\
\hline$\cdot, 999$ & $\cdot, 9 Y \varepsilon$ & $\cdot, \wedge 00$ & $1,7 \wedge 9$ & $1 \varepsilon, \Upsilon 4$ & $1,9 \cdot v$ & $|\varepsilon, 77|$ & ثا & الدحرجة بالكرة ذهابا وايابا بين \ شواخص & & $.1 \varepsilon$ \\
\hline
\end{tabular}

من النظر للجدول رقم (1) والذي يبين الأوساط الحسابية والانحرافات المعيارية والثبات والصدق والموضوعية قام الباحثون باستبعاد اختبار السيطرة على الكرة •0 فما فوق وهو احد اختبارات لعبة كرة القدم لعدم حصوله على درجة الثبات اللازمة للاختبار المقبول لغرض دخوله في التحليل إذ بلغت درجة ثبات هذا الاختبار (9 (0. . •)، وبهذا أصبح

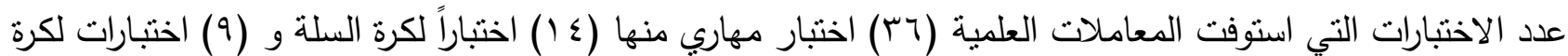

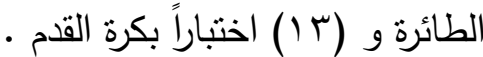
ب-7 المعاملات العلمية للاختبارات المهارية المرشحة للتحليل العاملي : قام الباحثون باستخراج المعاملات العلمية للاختبارات بالصيغة الآتية : الثبات : نم استخراج معامل ثبات الاختبار عن طريق تطبيق الاختبار وإعادة نطبيقه على عينة البحث الاستطلاعية وتم

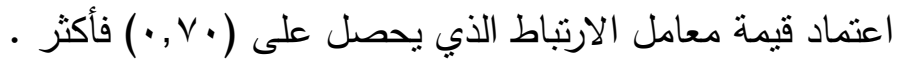


الصدق : استخدم الباحثون أنواع مختلفة من الصدق منها الصدق الظاهري الذي يشير إلى "'المدى الذي يقيس بموجبـ

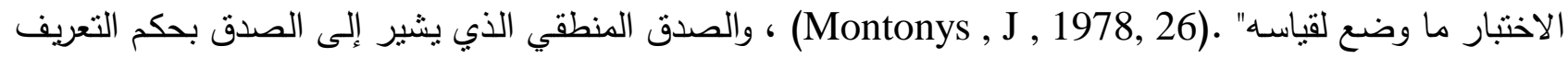

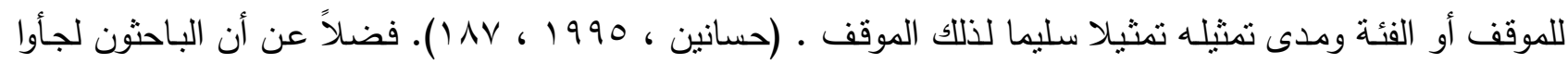

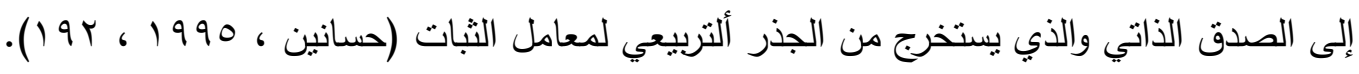
الموضوعية : تم إيجاد معامل الموضوعية عن طريق إيجاد معامل الارتباط بين درجتي محكمين لأداء للعينة الواحدة في الوقت نفسه وكل على حدأ.

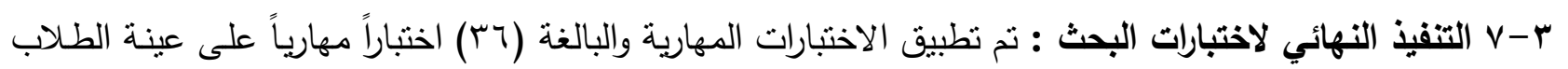

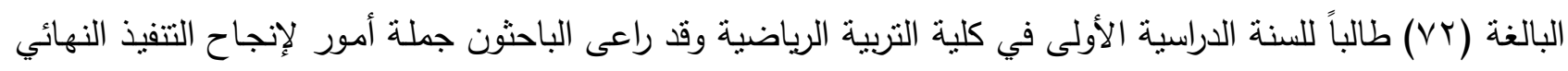

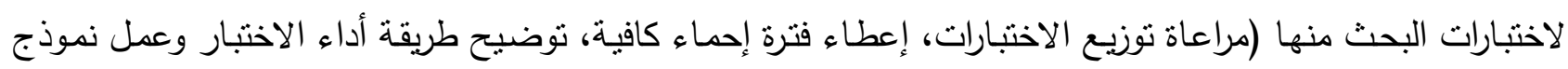
لكل اختبار ). ب-1 المعالجـات الإحصائية : تم استخدام حزمـة البرامج الإحصائية (SPSS) لإيجـاد المعالجـات الإحصائية الآتية:

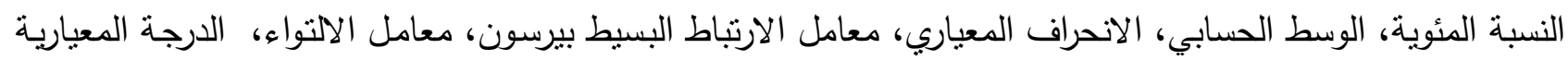

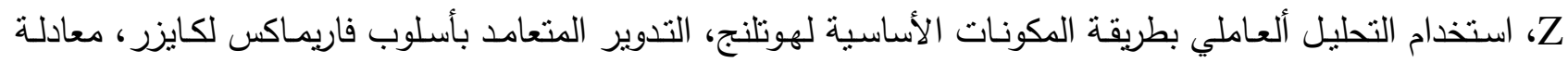
بيرت وبانكس لحساب الأخطاء المعيارية للتشبعات على العوامل المستخلصة، ومن الجدير بالذكر انه تم إعادة معالجة البيانات أكثر من مرة للتأكد من صحة العمل الإحصائي وجاءت النتائج مطابقة . . 1\% للتحليل الأولي . ع - عرض ومناقشة النتائج :

ع - 1 عرض النتائج وتحليلها ومناقشتها للعبة كرة السلة :

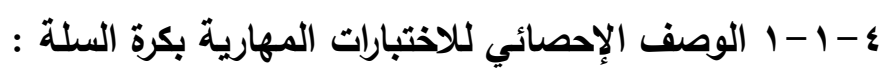

الجدول رقم (ץ)يبين الأوساط الحسابية والانحرافات المعيارية والمنوال ومعامل الالتواء للاختبارات المهارية بكرة السلة

\begin{tabular}{|c|c|c|c|c|c|c|c|}
\hline الالتواء & 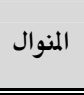 & الانحراف المعاري & الحسابي & | وحدة القياس & اسم الاختبار & 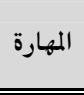 & رق الاختبار \\
\hline$\cdot, 190$ & $79, \cdots$ & Q,१९० & TV,Qน. & 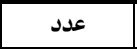 & | التمرير بالدفع & \multirow{5}{*}{ 雱 } & 1 \\
\hline • & $v, \cdots$ & 1,0v. & $\Lambda, \cdot \sum 1$ & عدد & لدقة التمرير على مستطيلات (IY) م & & r \\
\hline$\cdot, r \leqslant 4$ & $9,1$. & $1,1 \vee 9$ & q,rq. & ثا & التمرير إلى حائط & & $r$ \\
\hline$\cdot, \cdot 91-$ & $10, \cdot \cdot$ & $r, \Delta \leq Q$ & $1 \varepsilon, \mathrm{VQ}$ & 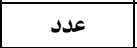 & حائط الارتداد & & $\varepsilon$ \\
\hline$\cdot, r \mathrm{VI}-$ & ro,** & $r, 1 \leq \varepsilon$ & $r \mu, \Lambda \mu r$ & عدد & |التمرير بيد واحدة من أعلى على دوائر هسافة (ه, • )م & & 0 \\
\hline 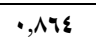 & $11, r_{0}$ & $1,7 \mathrm{rq}$ & $1 Y, 709$ & ثا & |المحاورة بالكرة ذهابا وإيابا بين ع شواخص & \multirow{4}{*}{$\begin{array}{l}\overline{3} \\
3 \\
: 3\end{array}$} & 9 \\
\hline$\cdot, 79 \varepsilon$ & $11,9$. & $1, \leqslant \leqslant 9$ & $1 Y, 9 \cdot 7$ & ثا & المحاورة بالكرة بين r شواخص مذتهية بالتصويب & & $\checkmark$ \\
\hline$\cdot, 1 \cdot r$ & $1 r, 9$. & 1,rq. & $|r, \cdot \xi|$ & ثا & المحاورة بالكرة ذهابا وإيابا بين \ شواخص & & $\wedge$ \\
\hline$\cdot, \cdot \bullet \cdot$ & $0,9$. & $\cdot, 001$ & $0,9 Y \wedge$ & ثا & |المحاورة بالكرة بخط مستقيم حول شاخص واحد & & 9 \\
\hline • & $£ \mathrm{~V}, 19$ & $\Lambda, \vee ฯ 4$ & $\varepsilon 9,9 \cdot 0$ & معيارية & | التصويب من الوثب & \multirow{5}{*}{$\begin{array}{l}\overline{7} \\
3 \\
3\end{array}$} & 1. \\
\hline$\cdot$, r०q & $19, \cdot \cdot$ & $0,1 \mu \varepsilon$ & IV,rM & عدد & | التصويب من أسفل السلة لمدة (·ץ) ثانية & & 11 \\
\hline$\cdot, 14-$ & IV,,$\cdot$ & $\varepsilon, Y \backslash \xi$ & $19, \times 91$ & 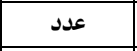 & |التصويب الأمامي & & ir \\
\hline 1,190 & $\Lambda, \cdots$ & $\varepsilon$, Y & Ir,qVY & 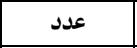 & | التصويب الجانبي & & ir \\
\hline P, & $\mathrm{v}, \cdot \cdot$ & I,V৭々 & $v, \cdot \xi 1$ & 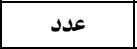 & الرمية الحرة & & $1 \varepsilon$ \\
\hline
\end{tabular}

من الجدول رقم (Y) نلاحظ أن معظم قيم الأوساط الحسابية هي اكبر من الانحرافات المعيارية وهو ما يعطي مؤشراً واضحاً لانتظام العينة اذ يؤكد ( المعماري ، . . . ب) إلى "أن ظهور الوسط الحسابي اكبر من الانحراف المعياري

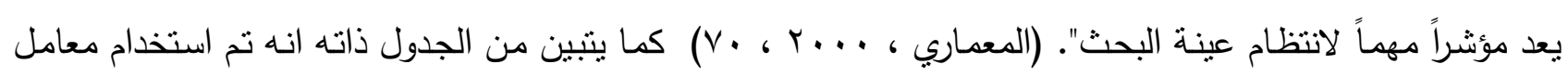

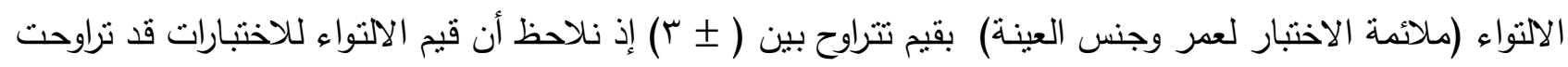




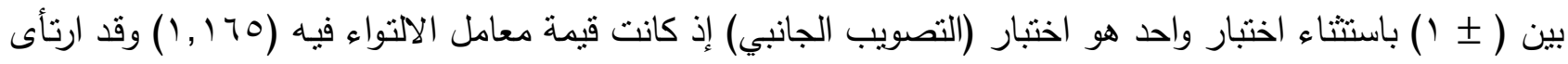
الباحثون أخذه ضمن الاختبارات لأنه لم بتطرف بشكل كبير عن باقي الاختبارات وهو في كل الأحوال واقع ضدن حدود

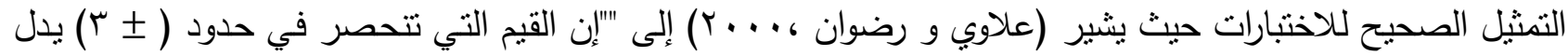

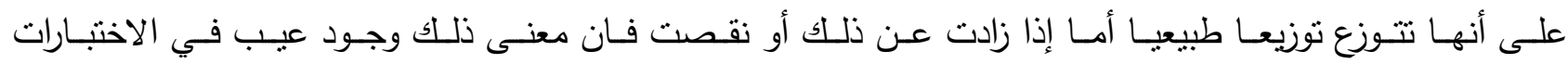

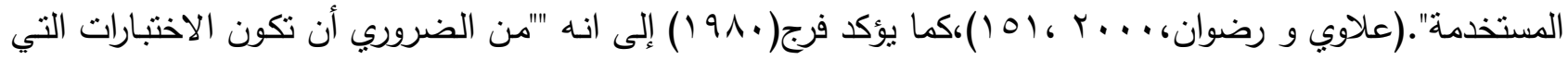
يتم اختيارها لإدخالها إلى التحليل العاملي بدرجة ومستوى واحد من الصعوبة فالتفاوت والاختلاف الكبيرين بين بعضها

$$
\text { البعض سوف يقلل من الارتباطات بينها" (فرج ، • • 191 ، • (V). }
$$

ع - - - مصفوفة الارتباطات البينية للاختبارات المهارية بكرة السلة

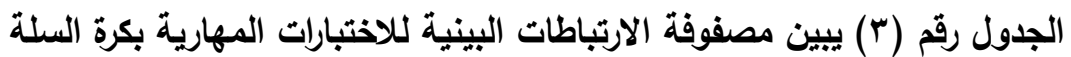

\begin{tabular}{|c|c|c|c|c|c|c|c|c|c|c|c|c|c|c|}
\hline $1 \varepsilon$ & Ir & Ir & 11 & 1. & 9 & $\Lambda$ & V & 7 & 0 & $\varepsilon$ & $\mu$ & $r$ & 1 & \\
\hline & & & & & & & & & & & & & $1, \ldots$ & 1 \\
\hline & & & & & & & & & & & & $1, \cdots$ & $\cdot$, IVY & $r$ \\
\hline & & & & & & & & & & & $1, \cdots$ & •,rIM_ & $\cdot, \cdot r \Lambda$ & $r$ \\
\hline & & & & & & & & & & $1, \cdots$ & $\cdot, \cdot v$ & $\cdot, r V \cdot *$ & $\cdot, \cdot O r$ & $\varepsilon$ \\
\hline & & & & & & & & & $1, \cdots$ & $\bullet, \cdot \leq \varepsilon$ & •, IVo & $\cdot, \cdots 9-$ & $\bullet, I r$. & 0 \\
\hline & & & & & & & & $1, \cdots$ & • וma- & $\bullet, \bullet \bullet$ & $\cdot, \cdots \bullet-$ & $\cdot, 10 \varepsilon-$ & $\cdot, \cdot \vee \bullet-$ & 9 \\
\hline & & & & & & & $1, \cdots$ & $\cdot, \cdot 79$ & $\cdot, \cdot r \Lambda-$ & $\cdot, \cdot O V$ & $\bullet, \mid \varepsilon \cdot-$ & س", & $\cdot, \cdot 79$ & v \\
\hline & & & & & & $1, \cdots$ & $\cdot, .97$ & $\cdot, \cdot \varepsilon \varepsilon$ & $\cdot, 1 \cdot 0$ & $\cdot$, IrV & $\cdot, 1 \cdot r-$ & $\cdot,|v|$ & $\cdot, \cdot 19-$ & $\wedge$ \\
\hline & & & & & $1, \cdots$ & $\cdot, \cdot \leq \varepsilon-$ & • IMr & or, & •, & $\cdot, \cdot r+$ & $\cdot, 194$ & $\cdot, \cdot 10-$ & $\cdot, \cdot \vee \varepsilon$ & 9 \\
\hline & & & & $1, \cdots$ & $\cdot, \cdot 01$ & $\cdot, 00$ & $\cdot, 1 \cdot \varepsilon$ & $\cdot, 07$ & $\cdot, \cdot 70$ & $\cdot, 00$ & $\cdot, \cdots q$ & -, & $\cdot, \| \varepsilon$ & 1. \\
\hline & & & $1, \cdots$ & $\cdot, \cdot \mu \Lambda-$ & $\cdot, \cdot 0 \cdot-$ & $\cdot, \cdot \varepsilon Y$ & • & •, YצY & $\cdot, \cdot \vee 7$ & - & $\cdot|\wedge|$ & $\cdot, r \cdot V-$ & $\cdot, Y \backslash Y$ & 11 \\
\hline & & $1, \cdots$ & •, YYq & $\cdot, \cdot \varepsilon Y-$ & $\cdot, \cdot \wedge 1-$ & $\cdot, \cdot 9 V$ & $\cdot, \cdot 11-$ & - $Y 79_{*-}$ & $\cdot, \cdot Y Y-$ & $\cdot, .09$ & $\cdot, I V \varepsilon-$ & $\cdot, \cdot V V$ & $\cdot,+11-$ & ir \\
\hline & $1, \cdots$ & $\cdot, \cdots r-$ & $\cdot, 10 Y-$ & • וry & •, $\cdot r_{\mu}$ & $\cdot|r|-$ & $\cdot, 01$ & $\cdot, 1 \leqslant \mu_{-}$ & $\cdot, \boldsymbol{M} \Lambda_{*}$ & $\cdot, 1 \cdot r$ & $\cdot, \cdot 9 \cdot-$ & $\bullet, \wedge 0$ & •,YYI- & ir \\
\hline $1, \cdots$ & •, $Y \backslash \leqslant-$ & $\bullet, 11$. & $\cdot, I \wedge \vee$ & •, 194_ & $\cdot, 1 \cdot v$ & $\cdot, Y 01_{*}$ & $\cdot, \mid \leqslant \wedge-$ & $\cdot, I V Y-$ & $\cdot, r_{0}$ & $\cdot, 1 \cdot 1$ & $\cdot, 101$ & $\cdot|| v \mid$ & $\cdot|\Lambda|$ & $1 \varepsilon$ \\
\hline
\end{tabular}

* قيمة (ر) الجدولية (Y Y Y, ·) عذد مستوى معنوية (ه , , ) ودرجة حرية (ن-Y)

يشير( المنسي ، 9 (19) لكي نستطيع أن نصل إلى التحليل العاملي لا بد أن نقوم بخطوة حساب معاملات الارتباط بين الاختبارات الموضوعة قيد البحث ومن ثم توضـع النتائج التي نحصل عليها في إطار مصفوفة ارتباطيه

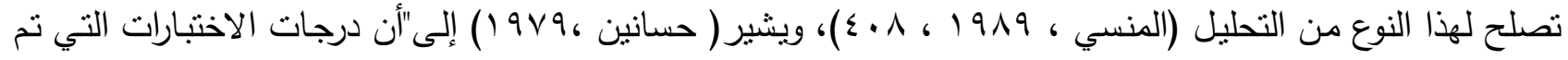
معاملتها أدت إلى حدوث هذا الارتباط وبالتالي فانه يمكن القول إن الوصـول إلى التحليل العاملي يتدرج من درجات

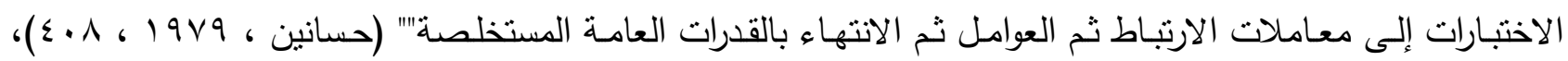
ومن الجدير بالذكر أن الدرجات التي تم استخلاصها من الاختبارات التي جرى تتفيذها قد تعرضت إلى معالجة إحصائية كان الهدف منها توحيد وحدة القياس المستخدمة وذلك لان الاختبارات تتوعت في قياسـاتها من قياس للزمن الكلي أو مجموع الدرجات الكلي إلى عدد التكرارات ولذلك كانت هناك حاجة إلى توحيد وحدة القياس المستخدمة باستخدام الدرجة المعيارية (Z) وهو ما انطبق على المصفوفات الثناث ع - ا-ب الجذور الكامنة ونسب التباين والتباين المتجمع للعوامل :

جدول رقم (؛) يبين الجذور الكامنة ونسب التباين والتباين المتجمع لعوامل الاختبارات المهارية بكرة السلة

\begin{tabular}{|c|c|c|c|}
\hline التباين المتجمع & نسبة التباين & الجذور الكامنة" & العوامل \\
\hline $1 \%, \wedge \Delta 0$ & Ir, & $1,9 \varepsilon$. & 1 \\
\hline 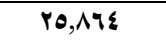 & $1 r, \cdots q$ & $1,4 \times 1$ & $r$ \\
\hline rq,Vos & 1.,^৭. & 1,oro & $\mu$ \\
\hline
\end{tabular}


إن الجذور الكامنة ونسب التباين والتباين المتجمع تعد مفاهيم أساسية نسعى لتقدير قيمها الإحصائية

لاستخلاص العوامل وهذه المفاهيم ترتبط بعضها ببعض ، ونلاحظ ان قيمة الجذر الكامن للعامل (1) (1) بلغت

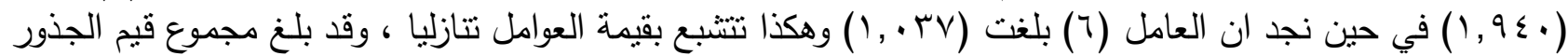

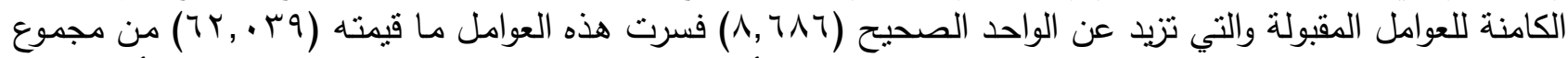

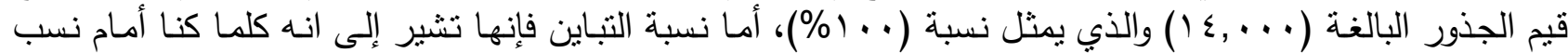
مرتفعة كلما كنا أمام عوامل أكثر أهمية وان كانت لا تتوفر حتى الآن معايير لتقدير أهمية العامل ففي العامل (1) نجد التهد

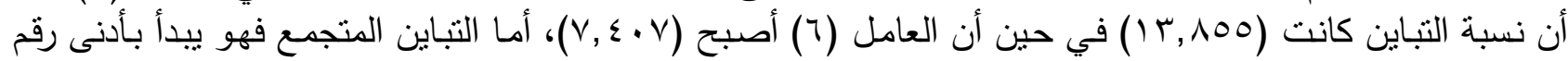

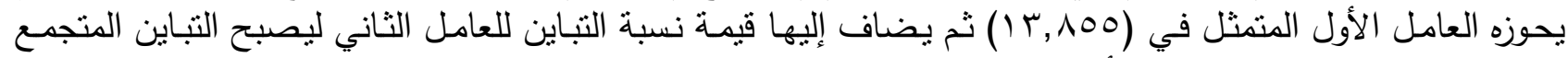

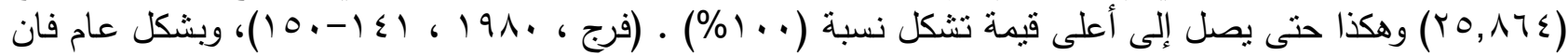

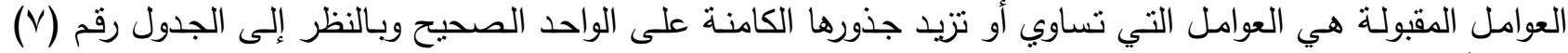

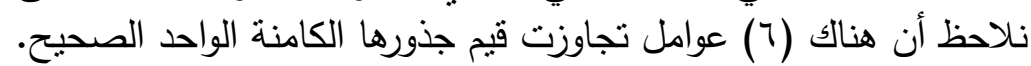

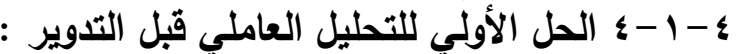

جدول رقم (ه) يبين مصفوفة العوامل قبل التدوير للاختبارات المهارية بكرة السلة

\begin{tabular}{|c|c|c|c|c|c|c|}
\hline \multicolumn{6}{|c|}{ العوامل } & \multirow{2}{*}{ رقم الاختبار } \\
\hline 9 & 0 & $\varepsilon$ & $r$ & $r$ & 1 & \\
\hline - & $\cdot, \cdot Y \wedge V$ & $\bullet, 07$. & - & $\cdot, \cdot 71$ & $\bullet, \mathrm{M} \wedge$ & 1 \\
\hline •, Y7q- & $\cdot, r q 1-$ & $\cdot, \cdot Y r$ & $\cdot, \cdot r r$ & $\cdot, 79$. & $\cdot, Y \otimes \varepsilon$ & $r$ \\
\hline$\cdot, \cdot 1 \leqslant-$ & $\cdot, Y \wedge H_{-}$ & $\cdot, \mu \wedge V$ & $\cdot, 1 \wedge \varepsilon$ & $\cdot, \Delta 9 \cdot-$ & $\cdot, 190$ & $r$ \\
\hline$\cdot, .91-$ & $\cdot, r \leqslant 0-$ & $\cdot, Y M r$ & $\cdot, 10 \mathrm{~V}$ & •, ¿ฯV & $\cdot, M \backslash \Lambda$ & $\varepsilon$ \\
\hline$\cdot, 990$ & $\cdot, \cdot\{r-$ & $\cdot, r V I$ & $\cdot, 7+1$ & $\cdot, \cdot V I-$ & $\cdot, r \leqslant r$ & 0 \\
\hline ",YY. & •, Yrs - & $\cdot, r \otimes \Lambda$ & $\cdot, r \diamond \Delta-$ & $\cdot, \cdot 9 r-$ & •,OTY- & 9 \\
\hline$\cdot, r \leqslant q$ & $\cdot, r \leqslant q$ & $\cdot, Y \leqslant \Lambda$ & $\cdot, \cdot 90-$ & •, Маq & $\cdot, r \leqslant 0-$ & $V$ \\
\hline •,VYr & $\cdot, 1 \leqslant r_{-}$ & $\cdot, \| 1$ & $\cdot, \bullet \wedge 9$ & •, rq & $\cdot, r \leq q$ & $\Lambda$ \\
\hline •,rlr- & $\cdot, r \otimes V$ & $\cdot, 119$ & $\cdot, \leq 4 Y-$ & •, r. & $\cdot, \mid \Lambda \Lambda-$ & 9 \\
\hline$\cdot, 100$ & ד & •, ¿qY & $\cdot, Y / 4$ & $\cdot, 1 \varepsilon \cdot$ & $\cdot, 194$ & 1. \\
\hline$\cdot, \cdot \mu \cdot$ & $\cdot, \& Y \wedge$ & $\cdot, \cdots \wedge-$ & $\cdot, \cdot M_{-}$ & $\cdot, \varepsilon \cdot \mu_{-}$ & $\cdot, \bullet \wedge \cdot$ & 11 \\
\hline $.1 \leqslant \varepsilon$ & $\cdot, \varepsilon \cdot \mu$ & $\cdot, 0 \cdots-$ & $\cdot, \bullet \vee \vee$ & $\cdot, 1 \wedge \varepsilon$ & $\cdot, \delta \mu r$ & Ir \\
\hline •, YMM- & $\cdot, \cdot$ & $\cdot, \cdot \wedge 9-$ & $\cdot, \mathrm{V} \backslash 1$ & $\cdot, r \leqslant 1$ & $\cdot, Y \mu \varepsilon-$ & ir \\
\hline$\cdot, \cdot 0 \cdot-$ & -, r৭०- & $\cdot, \cdot \vee \varepsilon$ & - וاس, • & $\cdot, \cdot \varepsilon \mu$ & .707 & $1 \varepsilon$ \\
\hline
\end{tabular}

تم تدوير العوامل في الجدول رقم (0) تدويراً متعامداً حيث استخدمت طريقة المكونات الأساسية (لهوتلنج) والتي

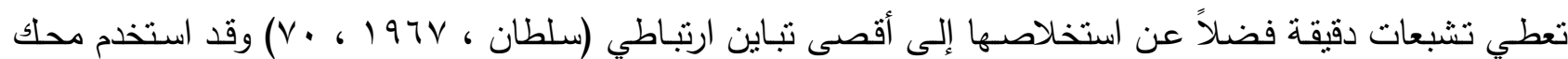

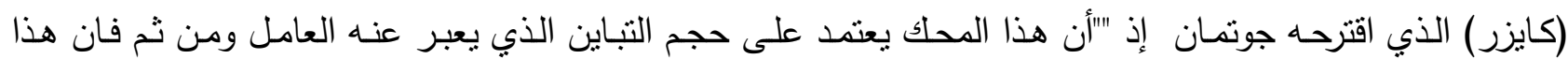

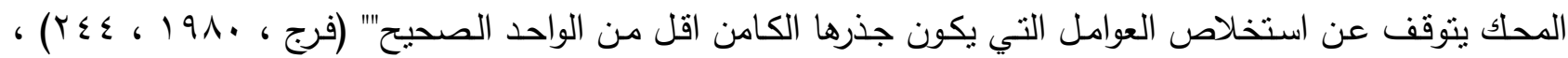

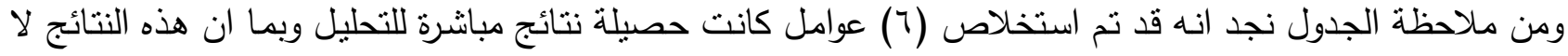


تخدم الإطار المرجعي للباحث ولا تكون بصيغة تؤهلها للتفسير الدقيق عليه سوف يلجأ الباحثون إلى إجراء التدوبر

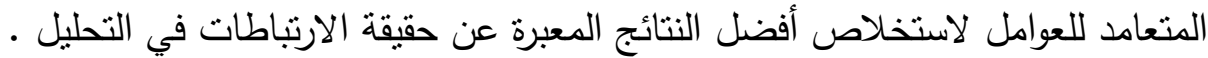

ـ - 1 -ه الحل النهائي للتحليل العاملي بعد التدوير:

جدول رقم (†) يبين مصفوفة العوامل بعد التذوير للاختبارات المهارية بكرة السلة

\begin{tabular}{|c|c|c|c|c|c|c|c|}
\hline \multirow{2}{*}{ قيم الشيوع } & \multicolumn{6}{|c|}{ العـوامــــل } & \multirow{2}{*}{ رقم الاختبار } \\
\hline & 9 & 0 & $\varepsilon$ & $r$ & $r$ & 1 & \\
\hline$\cdot, \times 10$ & •, & $\cdot, 17 V$ & •,Alr & $\cdot, \cdots V$ & $\cdot, \cdot\{1$ & •, lor & 1 \\
\hline$\cdot, 791$ & $\cdot, \cdot \sum \Lambda$ & $\cdot, \cdot \vee \varepsilon-$ & $\cdot, \cdot \Delta r$ & $\cdot, 1 \leqslant Y-$ & $\cdot, \bullet \wedge r$ & •,Alr & $r$ \\
\hline$\cdot, 70 \cdot$ & $\cdot, \cdot r \varepsilon-$ & •,YOY- & $\cdot, r m$ & $\cdot, 7 \mu$ & • & $\cdot, Y Y \cdot-$ & $r$ \\
\hline$\cdot, \varepsilon \cdot 0$ & $\cdot, \bullet \wedge \Lambda$ & $\cdot, \cdot 0 \cdot$ & $\cdot, \cdot V Y$ & $\cdot, 1 Y \varepsilon$ & $\cdot, \cdot \cdot r-$ & •, & $\varepsilon$ \\
\hline$\cdot, 0 \vee \varepsilon$ & $\cdot, \cdot P \varepsilon-$ & $\cdot, 19 \varepsilon$ & $\cdot, \cdot \Delta V$ & $\cdot, v \cdot v$ & $\cdot, \bullet \wedge \vee$ & $\cdot, 10 \mathrm{~V}$ & 0 \\
\hline$\cdot, 7 Y 1$ & $\cdot, 10 \cdot$ & $\cdot, I Y Y$ & $\cdot, 11 \varepsilon-$ & $\cdot, 194-$ & $\cdot, v \cdot r-$ & $\cdot, 191-$ & 9 \\
\hline$\cdot, 597$ & - lor & •, TY\& & $\cdot, \cdot \cdot V-$ & , YIYY- & $\cdot, \cdot 0 \cdot-$ & $\cdot, \cdot \vee \varepsilon$ & $v$ \\
\hline •,AYr & $\cdot, \wedge \varepsilon \theta$ & $\cdot, I V \mu$ & $\cdot, \cdot 90-$ & $\cdot, 11 \varepsilon$ &., .99 & •, YIq & $\Lambda$ \\
\hline$\cdot, 0 \cdot 1$ & •, Irq- & $\cdot, 17 r$ & • & •,OV०- & $\cdot, 1 \varepsilon \cdot-$ & $\cdot, \cdot \Delta r$ & 9 \\
\hline., $09 \cdot$ & $\cdot, \cdot 0 r-$ & $\cdot, \mathrm{V} \backslash 1$ & $\cdot, 1 \leqslant 0$ & $\cdot, 19$ & $\cdot, \cdot 00-$ & $\cdot,+$ rq- & 1. \\
\hline$\cdot, \Upsilon \wedge \varepsilon$ & $\cdot, 1 \cdot r$ & $\cdot, \cdot 9 \varepsilon-$ & $\cdot,\{0 \uparrow$ & $\cdot, r \cdot Y$ &., 010 & $\cdot, r \wedge \vee$ & 11 \\
\hline$\cdot, 971$ & $\cdot, 19 r$ & $\cdot, \cdots r-$ & $\cdot, \cdot 9 \cdot-$ & $\cdot, 1 \leqslant \varepsilon$ & $\cdot, \mathrm{V} \vee \wedge$ & $\cdot,+r \cdot-$ & Ir \\
\hline$\cdot$, • &., $019-$ & , YOS & $\cdot, \mu q$. & $\cdot, Y 70$ & $\cdot 19$ & $\cdot, \Gamma 19$ & ir \\
\hline •, Irv & $\cdot, \varepsilon \cdot Y$ & $\cdot,\{00-$ & •, \&Mq & $\cdot, \cdot Y q$ & $\cdot, 1 \cdot 9$ & $\cdot$, YOV & 18 \\
\hline \multirow[t]{2}{*}{$\Lambda, \Upsilon \wedge \uparrow$} & 1,rar & $1, r \wedge \varepsilon$ & 1,507 & 1,019 & 1,orr & $1,0 \leqslant 0$ & $*$ \\
\hline & 1\&,orq & 10,9Mr & 19, VIY & IV,\&or & IV,OYY & $I V, V \wedge V$ & $* *$ \\
\hline \multirow[t]{2}{*}{ rr. } & $9, \cdot 1 \varepsilon$ & $9, \wedge \wedge 0$ & $1 \cdot, \varepsilon$ & $1 \cdot, \Lambda Y \Lambda$ & $1 \cdot, \wedge \mathrm{VI}$ & $11, \cdot r o$ & 类券䄅 \\
\hline & $\cdot, \varepsilon \leqslant \Lambda$ & $\cdot, \mathrm{MA \Lambda}$ & •, r०q & $\cdot, r \cdot v$ & $\cdot, r V \Lambda$ & $\cdot, r 00$ & 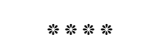 \\
\hline
\end{tabular}

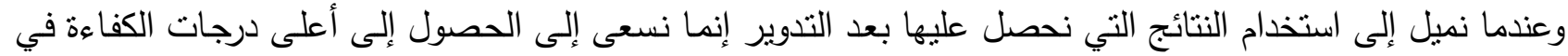

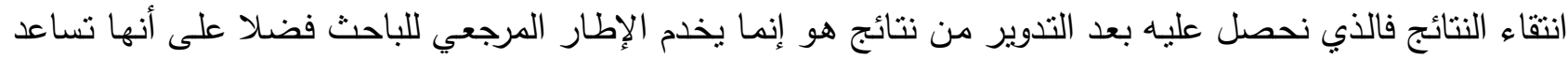

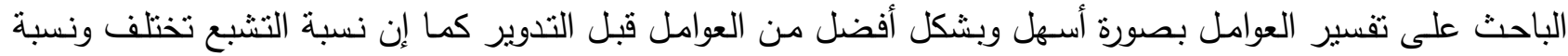

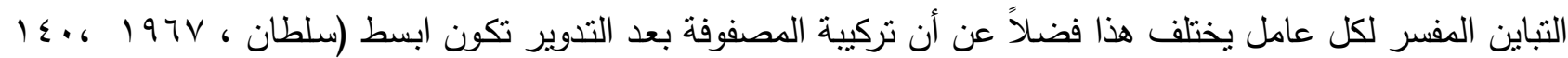

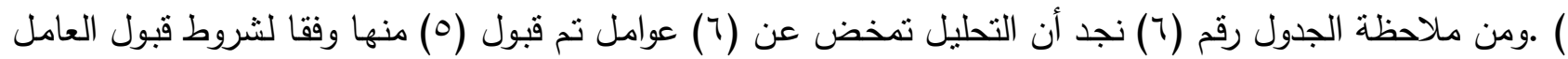
اختلفت في ارتباطات متغيراتها عما كان موجود قبل التدوير فقد بلغت قيم الجذور الكامنة للعوامل كالأتي العامل الأول

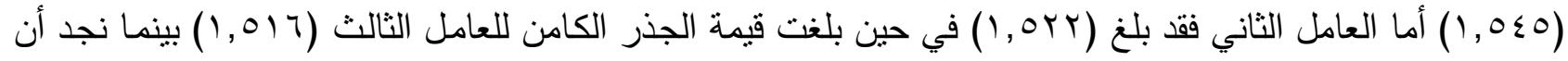

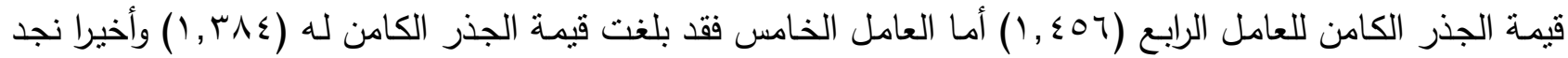

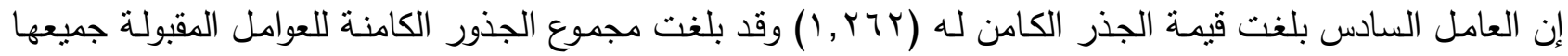

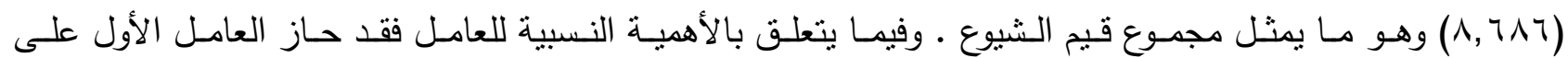
( V, VAV)

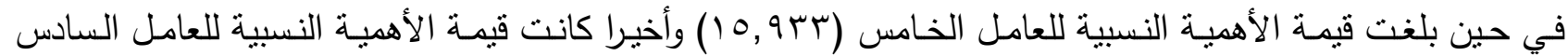

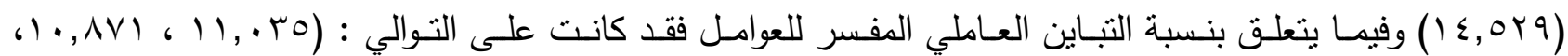
. $(9, \cdot) \leq$ ، $9, \wedge \wedge 0$ ، $) \cdot, \varepsilon$ ، $) \cdot, \wedge \uparrow \wedge$ 


\section{الصدق العاملي للافتبارات المارية المترحة في اختيار الطلاب المتدمين للقبول في..............}

ـ - 1-1 شروط قبول العامل والصدق العاملي للاختبار:إن قبول العوامل التي خلصت من التحليل العاملي كان وفقا اللشروط الآتية : أبروط

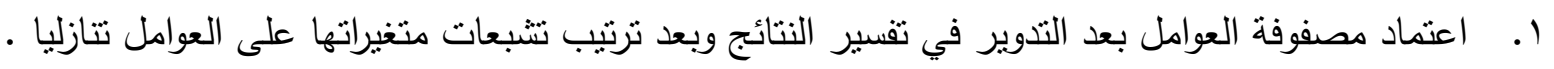

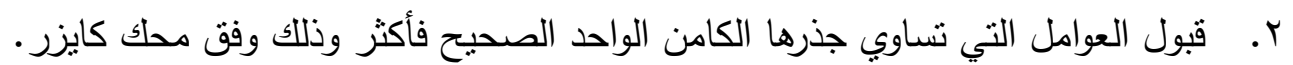

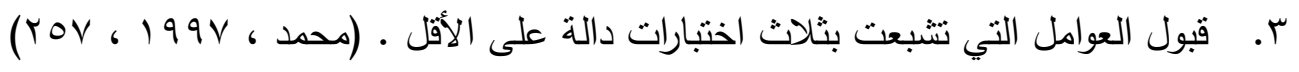

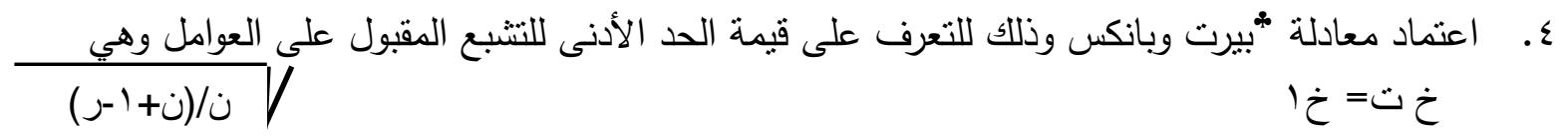

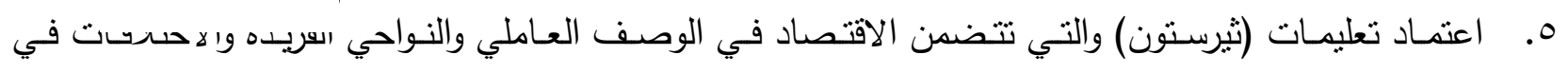

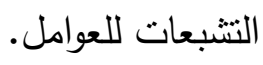

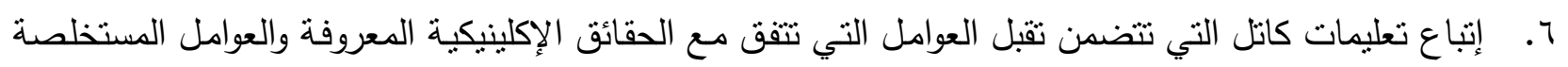

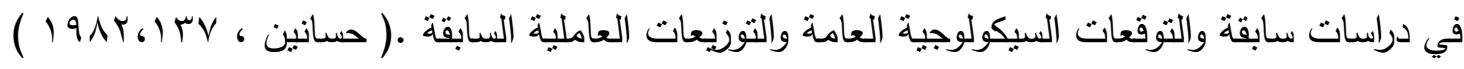

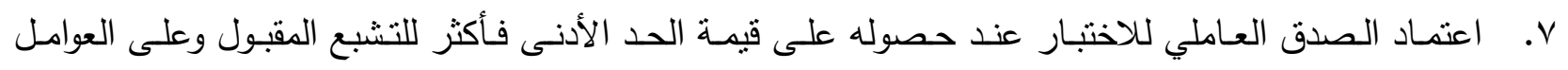
المقبولة فقط. ولا بد من الإنشارة إلى أن هذه الشروط تم الاستعانة بها في تفسير نتائج التحليل ألعاملي والصدق ألعاملي للاختبارات

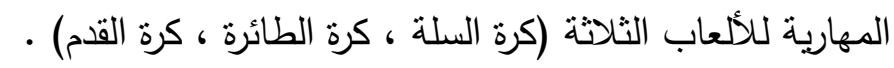

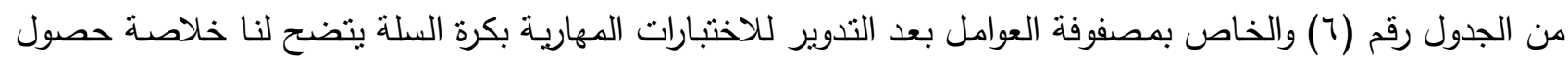

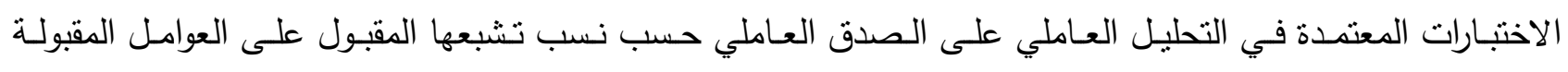

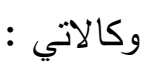

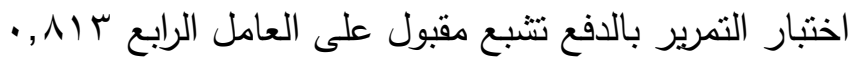

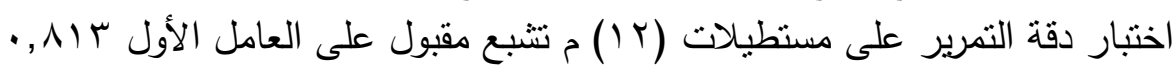

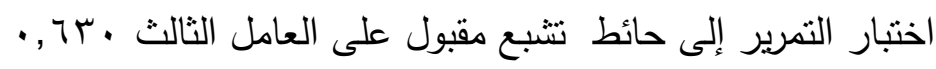

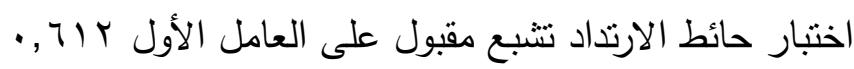

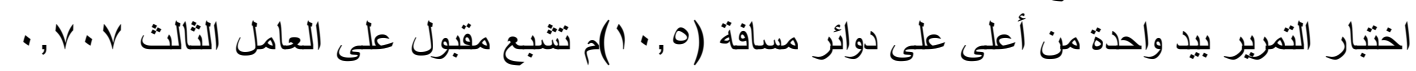

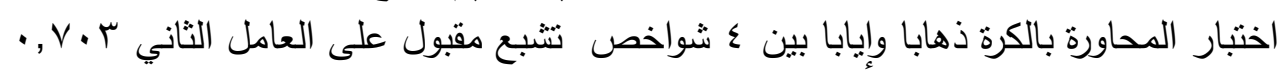

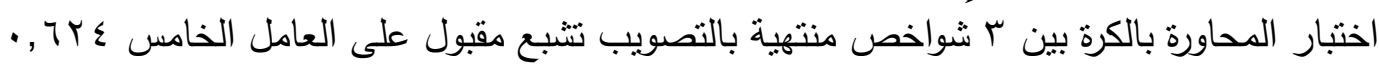

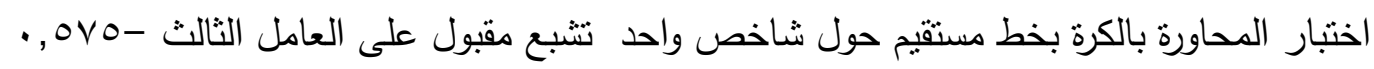

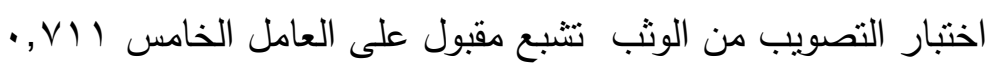

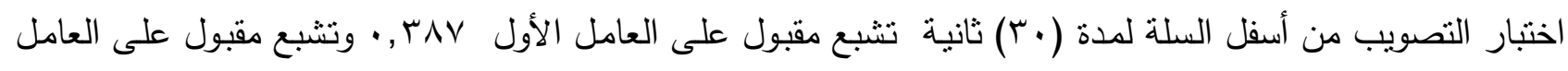

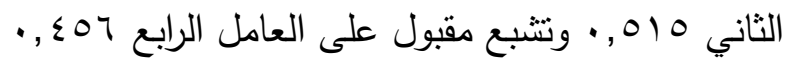

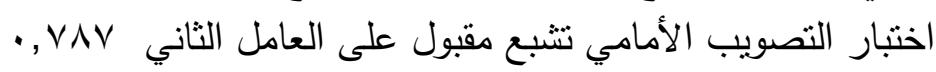

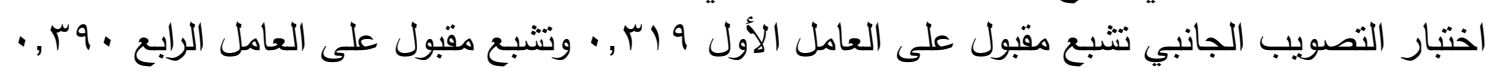

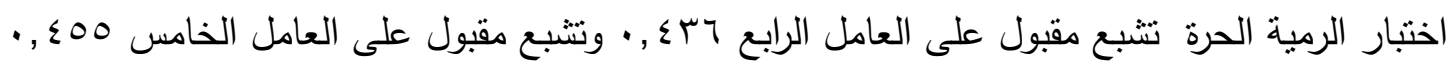

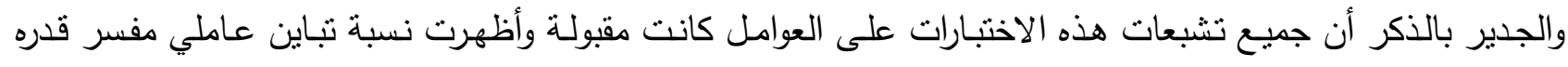

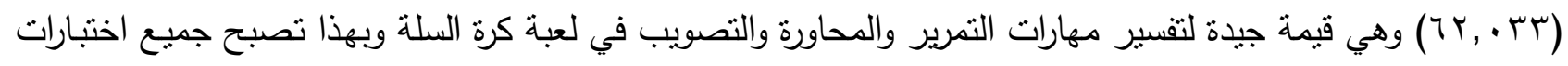

" خ ت = الخطأ المعياري للتثبع على العامل خ ا= الخطأ المعياري لمعامل الارتباط للعينة التي حلل ارتباطها عاملياً (يمكن الحصول عليه من جداول

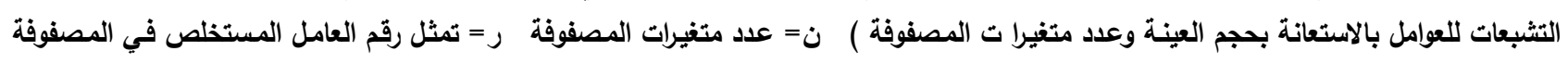


لعبة كرة السلة صـادقة عاملياً باسنتثاء اختبار المحاورة بالكرة ذهابـا وإيابـا بين( ب) شواخص وبذلك تصلح الاختبارات

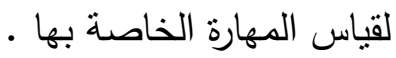

ع - ب عرض النتائج وتحليلها ومناقشتها للعبة الكرة الطائرة : ع - - 1 الوصف الإحصائي للاختبارات المهارية بالكرة الطائرة :

جدول رقم (V) يبين الأوساط الحسابية والاتحرافات المعيارية والمنوال ومعامل الالتواء للاختبارات المهارية بالكرة الطائرة

\begin{tabular}{|c|c|c|c|c|c|c|c|}
\hline الالتواء & 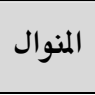 & الالمعياري & الحسابي & وحدة القياس & اسم الاختبار & المهارة & الاختبار \\
\hline$\cdot, \wedge \wedge 0$ & $r q, \cdots$ & $11, \mathrm{Va \varepsilon}$ & rq, $\leqslant \leqslant \varepsilon$ & 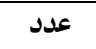 & 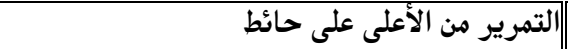 & \multirow{4}{*}{ 雱 } & .1 \\
\hline$\cdot, \leqslant \leqslant 0-$ & $9 \cdot, \cdots$ & $10, \mathrm{r} \wedge \mathrm{V}$ & or, lor & 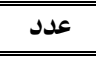 & |التمرير على حلقة كرة السلة & &.$r$ \\
\hline$\cdot$, IV. & rq, * & $9, Y 90$ & rr,Yrq & 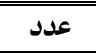 & |التمرير من الآسفل على حائط || & &.$\mu$ \\
\hline$\cdot, \mathrm{V} \bullet \varepsilon-$ & 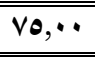 & 10,YYV & ir,olr & 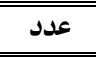 & |التمرير من الأعلى بالأصابع ومن الأسفل بالذراعين & &.$\varepsilon$ \\
\hline$\cdot, £ q \cdot-$ & or, $\cdots$ & $|r, \cdot \wedge|$ & $\varepsilon \theta, q \vee Y$ & 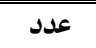 & |الإرسال من الآعلى أو من الأسفل . & \multirow{5}{*}{$\begin{array}{l}\overline{7} \\
\overline{3}\end{array}$} & .0 \\
\hline$\cdot, 099-$ & $\begin{array}{ll}Y, \cdots \\
\end{array}$ & 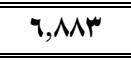 & rV,AVQ & 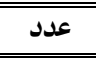 & |الإرسال من الأعلى ومن الأسفل & & .9 \\
\hline •, Vru- & 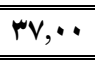 & 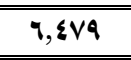 & Pr,YMq & 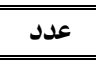 & |لإرسال & &.$V$ \\
\hline$\cdot, \& Y Y-$ & $7 \cdot, \cdot \cdot$ & $10, \cdots \varepsilon$ & or,7rA & 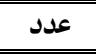 & |الإرسال الطويل & &.$\wedge$ \\
\hline$\cdot, 090$ & $0 \%, \cdots$ & IY,qVo & Tr,VYY & عدد & |الإرسال للنقاط الصعبة & & .9 \\
\hline
\end{tabular}

مـن خـلال الجدول رقم ( V) نلاحظظ إن قيم الأوسـاط الحسابية اكبر مـن قيم الانحرافـات المعياريـة الناتجـة للاختبارات وهو ما يؤكد انتظام العينة، أما بالنسبة لمعامل الالتواء فان جميع قيم معامل الالتواء للاختبارات كانت واقعة

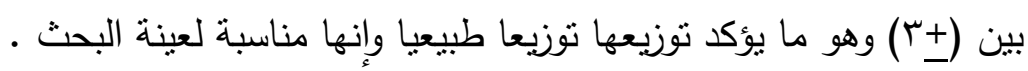

ع - - - مصفوفة الارتباطات البينية للاختبارات المهارية بكرة الطائرة : جدول رقم (^) يبين مصفوفة الارتباطات البينية للاختبارات المهارية بكرة الطائرة

\begin{tabular}{|c|c|c|c|c|c|c|c|c|c|}
\hline 9 & $\Lambda$ & $v$ & 9 & 0 & $\varepsilon$ & $r$ & $r$ & 1 & \\
\hline & & & & & & & & $1, \cdots$ & 1 \\
\hline & & & & & & & $1, \cdots$ & +, +99- & $r$ \\
\hline & & & & & & $1, \cdots$ & $\cdot, \cdots V-$ & $\cdot, 17 Y-$ & $r$ \\
\hline & & & & & $1, \cdots$ & $\cdot, Y \cdot \varepsilon$ & • & $\cdot, 1 \cdot r_{-}$ & $\varepsilon$ \\
\hline & & & & $1, \cdots$ & $\cdot, \| 11-$ & $\cdot,|\varepsilon|$ & $\cdot||||$ & • & 0 \\
\hline & & & $1, \cdots$ & $\cdot, 1 \cdot 1-$ & $\cdot, \cdot \Delta r_{-}$ & **, & $\cdot, 11 \varepsilon-$ & ט & 7 \\
\hline & & $1, \cdots$ & מיד & $\cdot, \cdot \leqslant 0-$ & $\cdot,+11$ & $\cdot, \cdot r V$ & $\cdot, \cdots \wedge$ & $\cdot, Y I V-$ & $v$ \\
\hline & $1, \cdots$ & $\cdot, \cdot \varepsilon V-$ & $\cdot, 111$ & $\cdot, 1 \cdot \varepsilon-$ & $\cdot, 1 \leq \varepsilon$ & $\cdot, \cdot r \varepsilon$ & $\cdot, \cdot \wedge 9-$ & $* \bullet, Y \leqslant q-$ & $\Lambda$ \\
\hline $1, \cdots$ & •, IrN- & • & $\cdot, \cdot \varepsilon V$ & $\cdot, \cdot \varepsilon V-$ & $\cdot, 19 \varepsilon-$ & $\cdot, \cdot$ YO- & "זצו, & $\approx \bullet, Y 90$ & 9 \\
\hline
\end{tabular}

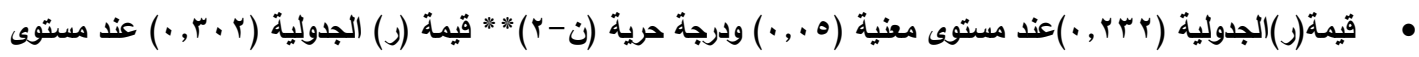

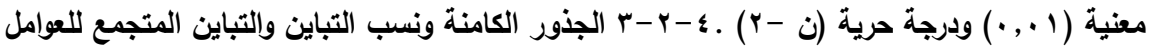

جدول رقم ( 9) يبين الجذور الكامنة ونسب التباين والتباين المتجمع للاختبارات المهارية بكرة الطائرة

\begin{tabular}{|c|c|c|c|}
\hline التباين المجتمع & نسبة التباين & الجذور الكامنة" & العوامل \\
\hline IN,V४q & $1 \wedge, \vee \bullet q$ & $1,4 \wedge$ & .1 \\
\hline
\end{tabular}

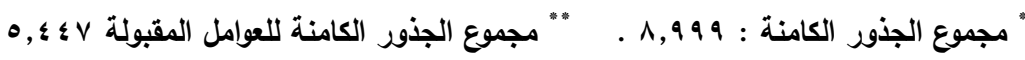




\begin{tabular}{|c|c|c|c|}
\hline$r_{0,} \cdot{ }^{\prime}$. & $|8, r y|$ & 1,879 &.$r$ \\
\hline$s 9,1\rangle_{0}$ & $1 \varepsilon,+\varepsilon 0$ & $1, Y q \varepsilon$ &.$r$ \\
\hline Tr,or. & $11, \varepsilon \cdot 0$ & " &.$\varepsilon$ \\
\hline $\mathrm{VI}, .99$ & $1 ., 079$ & $\cdot, 901$ & .0 \\
\hline 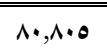 & $Q q, v \cdot 0$ & "•,AVr & . .7 \\
\hline 199,791 & $\Lambda, \wedge \wedge \uparrow$ & $\cdot, \wedge \cdot \cdot$ &.$V$ \\
\hline $90, \wedge T \varepsilon$ & 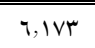 & (2,004 & $\bar{~} .^{\wedge}$ \\
\hline $1 \cdots, \ldots$ & $\varepsilon, \mid r v$ & • & .9 \\
\hline
\end{tabular}

من خـلال النظر إلى الجدول رقم ( 9) نلاحظظ أن هنـاك (ع) عوامل تجـاوزت قيم جذورها الكامنـة الواحد

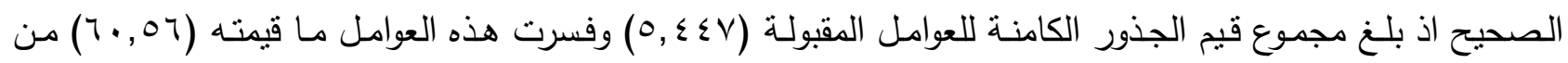

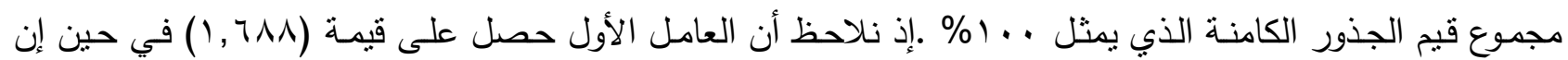

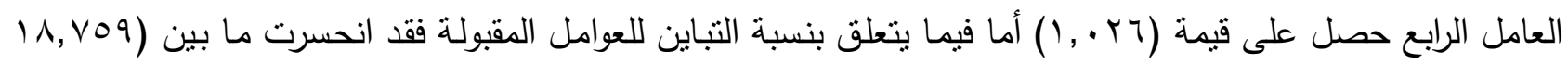

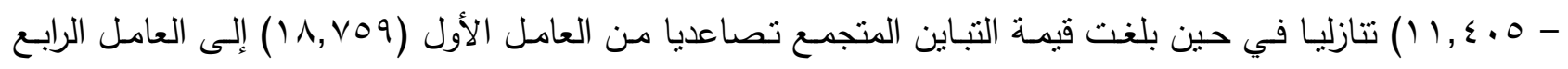

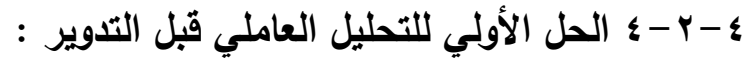
الجدول رقم ( • 1) يوضح مصفوفة العوامل قبل التدوير للاختبارات المهارية بكرة الطائرة

\begin{tabular}{|c|c|c|c|c|}
\hline \multicolumn{4}{|c|}{ العـوامـل } & \multirow{2}{*}{ رقم الاختبار } \\
\hline$\varepsilon$ & $r$ & $r$ & 1 & \\
\hline$\cdot, Y \cdot q$ & $\cdot, \mu l q-$ & $\cdot, 10 \cdot-$ & $\cdot, 791$ & 1 \\
\hline$\cdot, \mathrm{TOV}$ & •, YqV & $\cdot,\{0 \uparrow$ & $\cdot, \cdot 1 \cdot-$ & $r$ \\
\hline$\cdot, Y \backslash \varepsilon-$ & $\cdot,+r q$ & $\cdot,\{q \varepsilon$ & - OHY_ & $r$ \\
\hline$\bullet, \Delta \vee \bullet$ & $\cdot, 997$ & $\cdot, \cdot 1 \varepsilon-$ & -,ora- & $\varepsilon$ \\
\hline$\cdot, 1 \leq \varepsilon-$ & -ו וr, & $\cdot, 0 \leqslant 0$ & $\cdot, \cdot \vee \wedge$ & 0 \\
\hline • & $\cdot, \cdot 90$ & $\cdot, I r V-$ & $\cdot, \mathrm{MA}$ & 9 \\
\hline •, rrq_ & •,AYr & $\cdot, 1 \Lambda \cdot$ & $\cdot, \cdot 11-$ & $v$ \\
\hline$\cdot, \| r$ & $\bullet, \cdots v$ & $\cdot,\left\{\wedge \mu_{-}\right.$ & $\cdot, \varepsilon \varepsilon \cdot-$ & $\wedge$ \\
\hline$\cdot, \bullet \wedge \Lambda$ & 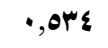 & • & $\cdot, 0 \leq 0$ & 9 \\
\hline
\end{tabular}

ـ - - - الحل النهائي للتحليل العاملي بعد التدوير :

جدول رقم (11) يبين مصفوفة العوامل بعد التدوير للاختبارات المهارية لكرة الطائرة

\begin{tabular}{|c|c|c|c|c|c|}
\hline \multirow{2}{*}{ قيم الشيوع } & \multicolumn{4}{|c|}{ العــوامــل } & \multirow{2}{*}{ رقم الاختبار } \\
\hline & $\varepsilon$ & $r$ & $r$ & 1 & \\
\hline$\cdot, 7 \varepsilon \varepsilon$ & $\cdot, \cdot \varepsilon \varepsilon$ & $\cdot, Y \wedge \Lambda-$ & •, & $\cdot, 4$. & .1 \\
\hline
\end{tabular}




\begin{tabular}{|c|c|c|c|c|c|}
\hline$\cdot, V \backslash Y$ & •, & $\cdot, \bullet \wedge 1$ & $\cdot, \cdot 94-$ & $\cdot, \wedge \wedge$ &.$r$ \\
\hline$\bullet, O \vee \varepsilon$ & $\cdot, \cdot 91$ & $\bullet, \cdot \vee 0$ & $\cdot, \|{ }^{\top} \wedge-$ & $\bullet, 1 \leqslant \varepsilon-$ &.$\mu$ \\
\hline •, • & $\cdot, 7 \cdot 9$ & - & $\cdot, \cdot \vee q_{-}$ & $\cdot, \varepsilon V^{\mu}-$ &.$\varepsilon$ \\
\hline س & $\cdot, \cdot \varepsilon V-$ & •, YYS- & $\cdot,\{\leqslant V-$ & $\cdot, \varepsilon Y 0$ & .0 \\
\hline$\cdot, 0 \vee Q$ & $\cdot, \cdot 99-$ & טזי, & $\cdot, \mathrm{V} 01$ & •, & .9 \\
\hline$\cdot, \vee \vee \wedge$ & $\cdot, \cdot 0 \%-$ & $\cdot, \wedge \vee \wedge$ & $\cdot, \cdot \leq \leqslant-$ & $\cdot, \cdot 9 V-$ &.$V$ \\
\hline$\cdot, \varepsilon P q$ & $\cdot, \cdots r$ & $\cdot, 1 \cdot Y-$ & $\cdot, 10 r$ & $\cdot, \pi V V-$ &.$\wedge$ \\
\hline$\cdot, 771$ & •, YMV & $\cdot, \diamond \leqslant \Lambda$ & $\cdot, 197$ & $\cdot, 019$ & .9 \\
\hline \multirow[t]{2}{*}{$0,\{0$} & 1,11 & $1, Y_{0}$ & $1,\{\Lambda$ & 1,71 & $\circ$ \\
\hline & $r \cdot, r q$ & Yr,qu & $r v, 10$ & $r q, \otimes \varepsilon$ & $\because$ \\
\hline \multirow[t]{2}{*}{$9 \cdot, 000$} & אוr, I & $1 r, \wedge \wedge q$ & $19, \leqslant \leqslant \varepsilon$ & 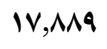 & 000 \\
\hline & $\bullet, M V r$ & מץr, & $\cdot, Y \wedge \varepsilon$ & $\cdot, r \otimes 0$ & 0000 \\
\hline
\end{tabular}

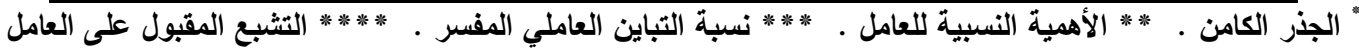

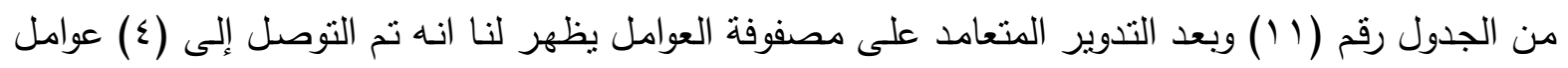

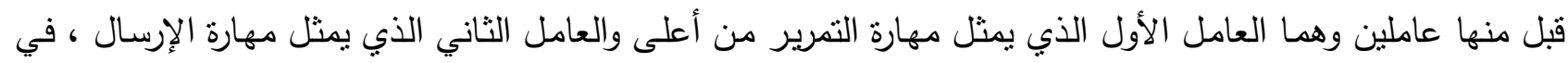

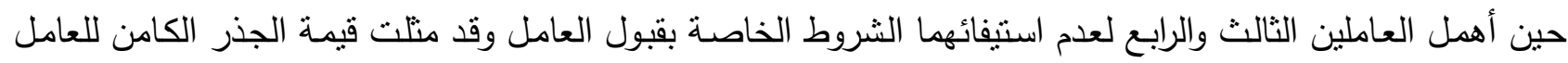

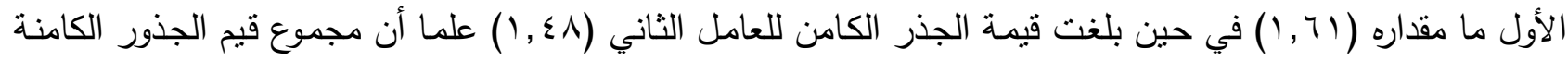

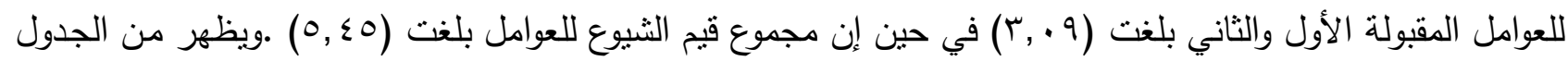

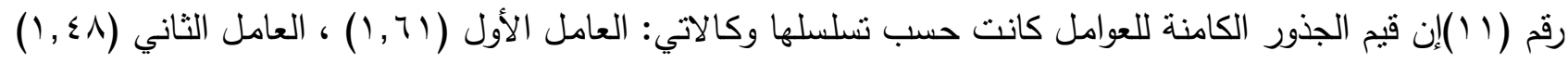

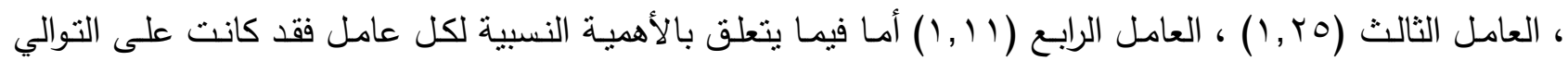

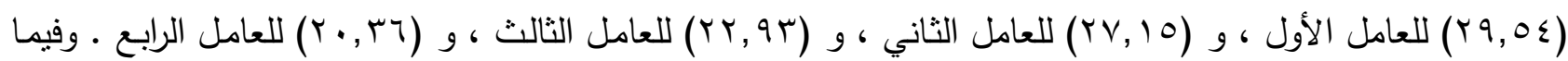

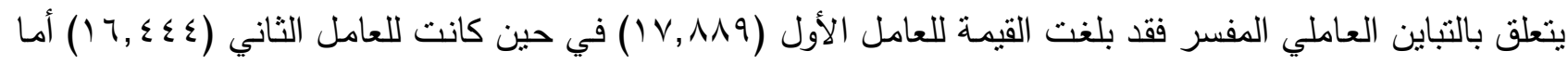

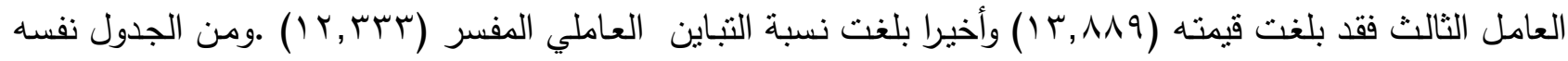

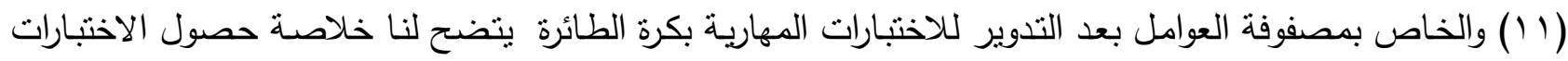

المعتمدة في التحليل العاملي على الصدق العاملي حسب نسب تشبعها المقبول على العوامل المقبولة وكالاتي :

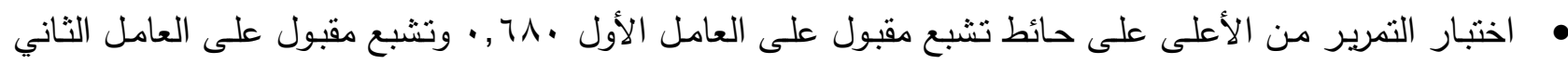
$\cdot, \Gamma$

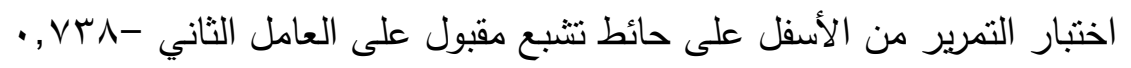

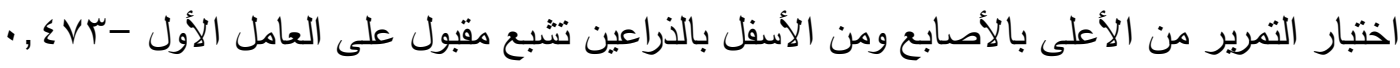

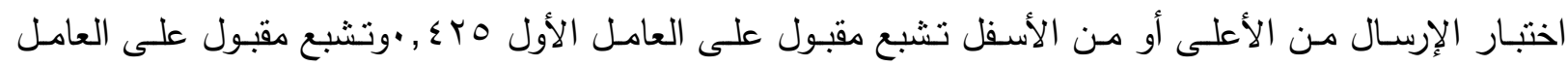
الثاني اختيان

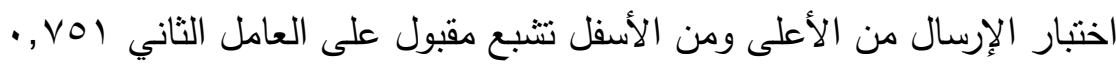

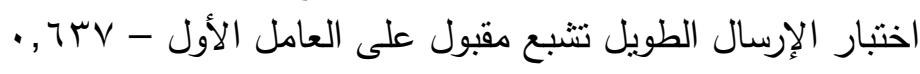

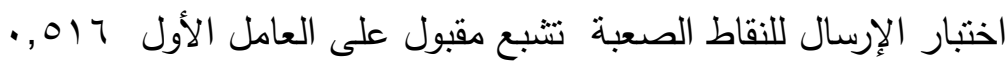

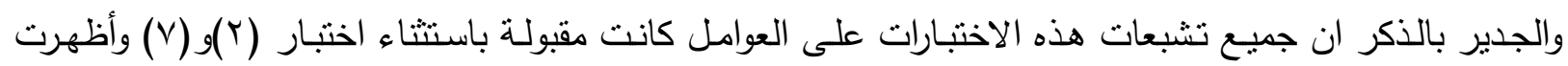
نسبة تباين عاملي مفسر قدره (000, • 7) وهي قيمة جيدة لتفسير مهارتي التمرير والإرسال في لعبة الكرة الطائرة وبهذا

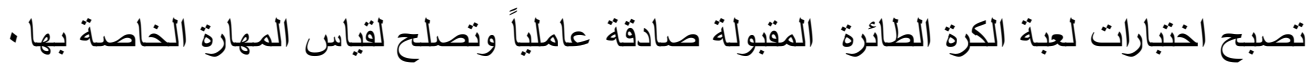

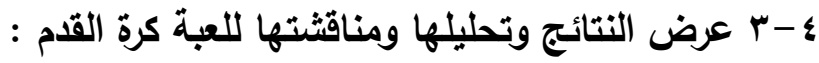
ع - - - الوصف الإحصائي للاختبارات المهارية بكرة القدم : جدول رقم (r ا ) الأوساط الحسابية والانحرافات المعيارية والمنوال ومعامل الالتواء للاختبارات المهارية بكرة القدم 


\begin{tabular}{|c|c|c|c|c|c|c|c|}
\hline معامل الالتواء & 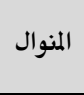 & الالمعياري & | الوسط الحسابي & وحدياس & اسم الاختبار & 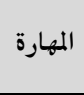 & الاختبار \\
\hline$\cdot, \wedge \uparrow$ & $\Delta q, \cdot \cdot$ & 11, r.o & $70,79 \varepsilon$ & 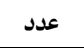 & | التصويب على المستطيلات الأربع & \multirow{4}{*}{$\begin{array}{l}\overline{3} \\
3 \\
3\end{array}$} & 1 \\
\hline •,AYo- & $1 \cdot, \cdot \cdot$ & $1, \varepsilon \backslash \varepsilon$ & 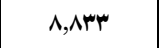 & 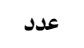 & | ل دقة التصويب على المرمى | & & r \\
\hline$\cdot, 1 \leqslant \varepsilon$ & $1 \xi, \cdot \cdot$ & $r, \cdot \wedge$ & $1 \leqslant, \leqslant \leqslant \varepsilon$ & 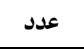 & |التصويب القريب على ثلاث دوائر مسافة r| متر & & $r$ \\
\hline$\cdot, \cdot r \cdot$ & $9, \cdot \cdot$ & $r, \cdot \sum \uparrow$ & $9, \cdot \sum 1$ & 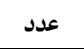 & |التصويب على هدف كرة القدم بداخله هدف كرة يد & & $\varepsilon$ \\
\hline$\cdot, \Delta \wedge r$ & rr, $\cdot \cdot$ & $11, r \cdot \Lambda$ & 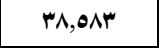 & 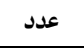 & | السيطرة على الكرة خلال • ب ثانية & \multirow{5}{*}{ 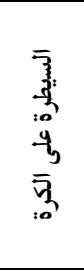 } & $\bullet$ \\
\hline$\cdot, \wedge \wedge q$ & $19, \S \cdot$ & $0,4$. & rI, \&or & ثا & |السيطرة على الكرة لأطول فترة ممكنة داخل دائرة & & 9 \\
\hline$\cdot, 9 \cdot 1$ & $1 \wedge, \cdot \cdot$ & v,rir & $r \varepsilon, \diamond \wedge r$ & 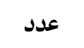 & |السيطرة على الكرة بجميع أجزاء الجسم عدا اليدين (محاولتين) & & $\checkmark$ \\
\hline$\cdot, 9 \leqslant \wedge$ & rl,,$\cdot$ & A,rYo & $\curlyvee \wedge, \wedge \cdot \bullet$ & 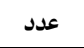 & |السيطرة على الكرة (ثلاث محاولات) & & $\wedge$ \\
\hline$\cdot, \varepsilon r \cdot$ & $89, \cdot \cdot$ & lo,rar & $V Y, \& 19$ & 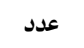 & | السيطرة على الكرة خلال دقيقة & & 9 \\
\hline$\cdot, \uparrow \cdot$ & $\mid r, \cdot \varepsilon$ & 1,irr & $\mid r, \Lambda \cdot \varepsilon$ & ثا & |الدحرجة بالكرة ذهابا وإيابا بين ه شواخص & \multirow{4}{*}{$\begin{array}{l}\overline{3} \\
1 \\
: 19\end{array}$} & 1. \\
\hline$\cdot, 1 \vee \wedge$ & ir,r. & 1,94r & 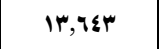 & ثا & |الدحرجة بالكرة ذهابا وإيابا بين r شواخص & & 11 \\
\hline •,vr. & $17,9$. & Y,०१६ & $\mid \Lambda, \varepsilon Y \wedge$ & ثا & | الدحرجة بالكرة ذهابا وإيابا بين ^ شواخص & & ir \\
\hline$\cdot, \wedge 99$ & Ir,YY & $r, \cdot 79$ & $10, \cdot v_{0}$ & ثا & |الدحرجة بالكرة ذهابا وإيابا بين ؟ شواخص & & ir \\
\hline
\end{tabular}

من الجدول رقم (r ( ) نلاحظ إن جميع قيم الأوساط الحسابية قد تجاوزت الاتحرافات المعيارية للاختبارات وهو

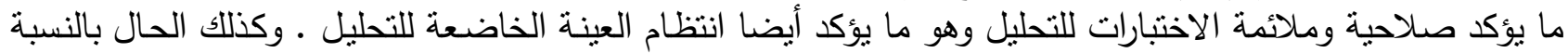

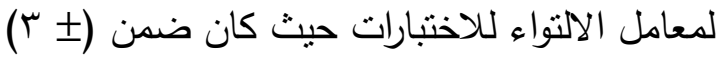

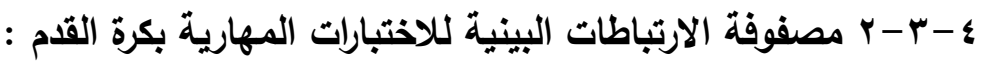

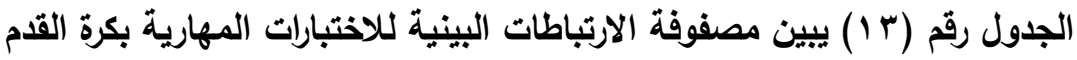

\begin{tabular}{|c|c|c|c|c|c|c|c|c|c|c|c|c|c|}
\hline ir & ir & 11 & 1. & 9 & $\wedge$ & $v$ & 9 & - & $\varepsilon$ & $r$ & $r$ & 1 & \\
\hline & & & & & & & & & & & & $1, \cdots$ & 1 \\
\hline & & & & & & & & & & & $1, \cdots$ & r & $r$ \\
\hline & & & & & & & & & & $1, \cdots$ & $\cdot, \cdot \mu$. & $\bullet, \bullet \wedge$ - & $r$ \\
\hline & & & & & & & & & $1, \cdots$ & $\cdot, \cdot v r$ & $\cdot, \cdot(\varepsilon)$ & $\cdot, 19 V$ & $\varepsilon$ \\
\hline & & & & & & & & $1, \ldots$ & - & •, & $\cdot, \cdot r r$ & $\cdot, 194-$ & 0 \\
\hline & & & & & & & $1, \cdots$ & $\cdot, \cdot v 1-$ & •,IVY & $\cdot, \cdot r \Lambda-$ & $\bullet, \cdot \vee \vee$ & $\cdot, I V r$ & 7 \\
\hline & & & & & & $1, \cdots$ & $\cdot, \cdot r q$ & $\cdot, \cdot \nabla \Lambda$ & - & $\cdot, \bullet \wedge r$ & - & $\cdot, r \cdot q-$ & $v$ \\
\hline & & & & & $1, \cdots$ & ד & $\cdot 1 \cdot 0$ & $\cdot, \cdot 97-$ & •,rll- & $\cdot, 1 \leqslant Y-$ & •IYr & $\cdot, 1 \leqslant V$ & $\wedge$ \\
\hline & & & & $1, \cdots$ & $\cdot, \cdot 1 \cdot-$ & $\cdot, \cdot V r$ & , & $* \cdot$, , ror & $\cdot, \cdot \mid r-$ & $\cdot, \cdot 10-$ & •, IrE & $\cdot, \cdot \Delta q_{-}$ & 9 \\
\hline & & $1, \cdots$ & $\cdot, \cdot \leq r$ & $\cdot, \cdot 9 \leqslant-$ & $\cdot, 1 \cdot \Lambda-$ & $\cdot, \cdot 9 \cdot-$ & $\cdot, \cdot 7 /$ & $\cdot, .99-$ & $\cdot, 1 \leqslant V-$ & $\cdot, \cdot 79-$ & $\bullet, \bullet \wedge 9$ & $\cdot, \cdot \Delta \Lambda-$ & 11 \\
\hline & & $\cdot, 1 \cdot v$ & $\cdot, \cdot 9 V$ & +,109- & ד & $\cdot, \cdot 7 r-$ & $\cdot, \cdots v$ & $*, Y \xi \vdash$ & $\cdot, \cdot Y \Lambda$ & $\cdot, \cdots r$ & $\cdot, 10 \cdot-$ & $\bullet, \bullet \varepsilon$. & Ir \\
\hline $1, \cdots$ & $\bullet, \cdots v$ & $* \bullet, Y \leqslant 1$ & $\cdot, 1 \cdot 1$ & $\cdot, 1 \cdot v$ & $\cdot, \cdot V \varepsilon-$ & $\cdot, \cdot r r-$ & $\cdot, \cdot\{Y-$ & - & $\cdot, \cdot r_{-}$ & $\cdot,+1 \varepsilon$ & $\cdot, \cdot 9 \cdot-$ & $\cdot, 191-$ & ir \\
\hline
\end{tabular}

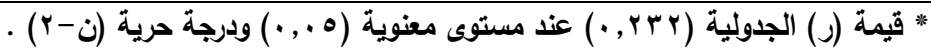

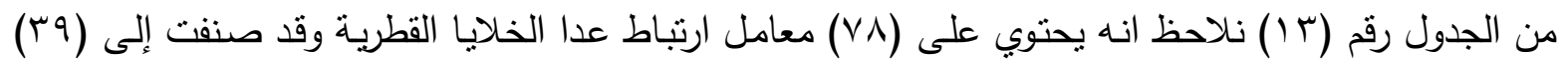

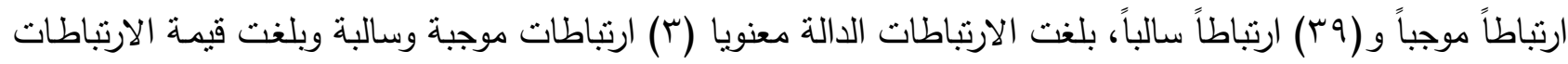

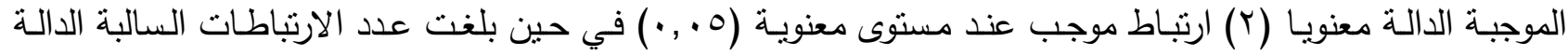

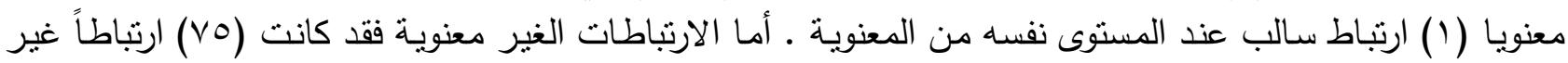


؟ - - الجذور الكامنة ونسب التباين والتباين المتجمع للعوامل

جدول رقم (ع ا ) يبين الجذور الكامنة ونسب التباين والتباين المتجمع للاختبارات المهارية بكرة القدم

\begin{tabular}{|c|c|c|c|}
\hline التباين المتجمع & نسبة التباين & الجذور الكامنة & العوامل \\
\hline $\mid r, 9 \Lambda$. & $\mid r, 9 \Lambda$. & $1, T A V$ & 1 \\
\hline$r 0, r \cdot q$ & Ir,req & $1,7 \cdot r$ & $r$ \\
\hline $\mathrm{MT}_{\mathrm{T}, \varepsilon \wedge \vee}$ & $11,1 \vee \wedge$ & 1, \&or & $r$ \\
\hline$\left\{T, Y T_{0}\right.$ & $৭, \vee \leqslant \wedge$ & 1,rTV & $\varepsilon$ \\
\hline $0 \&, 9 Y_{1}$ & $\Lambda, \uparrow \wedge \uparrow$ & $\because 1,1 r q$ & 。 \\
\hline Tr,OYT & $v, 7 \cdot 1$ & $\cdot, 9 \wedge \wedge$ & 1 \\
\hline$T 9, r Y$. & T,V V9V & $\cdot, \wedge \wedge \varepsilon$ & v \\
\hline$v_{0}, r v \wedge$ & $7, \cdot 01$ & $\cdot$, VM & $\wedge$ \\
\hline $11, r 00$ & $0, \wedge \vee V$ & $\cdot$, VT\& & 9 \\
\hline 1T,79V & $0,\{\leqslant r$ & $\cdot, v \cdot v$ & 1. \\
\hline 91,94 & $\varepsilon, q \mu q$ & $\cdot, T \leqslant Y$ & 11 \\
\hline $97, Y 9 \wedge$ & & $\cdot, 7 \cdot 4$ & ir \\
\hline $1, \ldots, \ldots$ & $r, v \cdot r$ & -,$\{\wedge r$ & ir \\
\hline
\end{tabular}

من خلال النظر إلى الجدول رقم (ع ا) نجد أن قيم الجذور الكامنة قد تدرجت بشكل نتازلي وان (0) عوامل

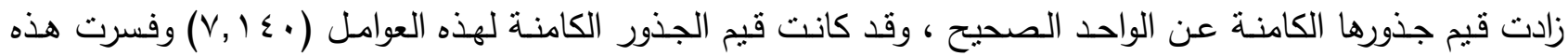

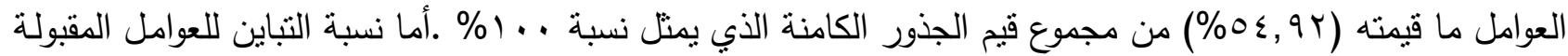

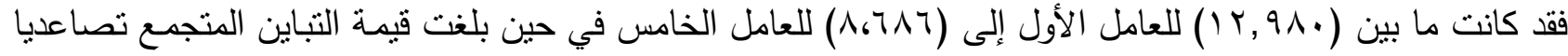

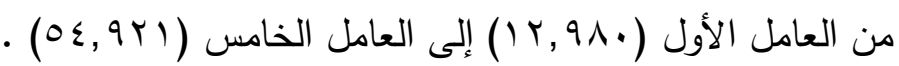

ع - - - الحل الأولي للتحليل العاملي قبل التدوير جدول رقم (0 1 ) يبين مصفوفة العوامل قبل التدوير للاختبارات المهارية لكرة القدم

\begin{tabular}{|c|c|c|c|c|c|}
\hline \multicolumn{5}{|c|}{ العـوامـل } & \multirow{2}{*}{ رقم الاختبار } \\
\hline 0 & $\varepsilon$ & $r$ & $r$ & 1 & \\
\hline$\cdot, \cdot 9 V-$ & $\cdot, \cdot 11$ & $\cdot,+91-$ & - , rq0 & $\cdot, \pi Y V$ & 1 \\
\hline e,Ylo & $\cdot, O V Y$ & e, & $\cdot, \varepsilon \cdot 1$ & $\cdot, \cdot \varepsilon r$ & $r$ \\
\hline •, $\mu \leqslant$ & $\cdot, \cdot r V-$ & •, & $\cdot, \cdot 9 \varepsilon-$ & $\cdot, 1 \leqslant \cdot-$ & $r$ \\
\hline
\end{tabular}

" مجموع الجذور الكامنة : . . . ب 1 .

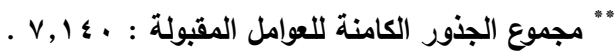




\begin{tabular}{|c|c|c|c|c|c|}
\hline$\cdot, 109-$ & •, lor & •,7ar & $\cdot, I V \varepsilon$ & $\cdot,\{10$ & $\varepsilon$ \\
\hline טrו, & מrו, & $\cdot, r q$. & $\cdot, Y Y_{1}$ & $\cdot, \triangle 9 V-$ & 0 \\
\hline$\cdot, 070$ & $\cdot, Y 1 \cdot-$ & $\cdot$, YVY & • & $\cdot, r V r$ & 9 \\
\hline •, INr & $\cdot$,IYI- & דr., & $\cdot, \cdot\{V-$ & - & $v$ \\
\hline •, & $\cdot, \mu 11-$ & •,07\&- & •, & $\cdot, 1 \cdot V$ & $\wedge$ \\
\hline$\cdot, 171$ & $\cdot, 1 \leqslant \Lambda$ & $\cdot, I \mu v$ & • & $\cdot, \varepsilon \mid V-$ & 9 \\
\hline$\cdot, \leqslant \leqslant Y$ & , 178- & $\cdot, 0 \vee 4$ & $\cdot, Y \backslash \leqslant-$ & •, IAY & 1. \\
\hline וחז, & •, \&Or & •, YYY & $\cdot, 011-$ & $\cdot, \cdot \vee q$ & 11 \\
\hline$\cdot, \| Y-$ & $\cdot, r V V-$ & $\cdot, \cdot 9 \varepsilon-$ & $\cdot, r v \cdot-$ & • & Ir \\
\hline$\cdot, \mu \varepsilon V$ & $\cdot, r \cdot q$ & $\cdot, 00$ & $\cdot, 040-$ & $\cdot,+71-$ & ir \\
\hline
\end{tabular}

ـ - - -ه الحل النهائي للتحليل العاملي بعد التدوير : جدول رقم (1 1 ) يبين مصفوفة العوامل بعد التدوير للاختبارات المهارية لكرة القدم

\begin{tabular}{|c|c|c|c|c|c|c|}
\hline \multirow{2}{*}{ قيم الشيوع } & \multicolumn{5}{|c|}{ العـوامـل } & \multirow{2}{*}{ رقم الاختبار } \\
\hline & 0 & $\varepsilon$ & $r$ & $r$ & 1 & \\
\hline$\cdot, \Delta 0 \mathrm{~V}$ & $\cdot, Y Y I$ & $\cdot, 1 \wedge \Lambda$ & $\cdot,\{9 \varepsilon$ & •, rq৯- & •, צฯฯ- & 1 \\
\hline$\cdot, 007$ & $\cdot, \cdot 1 \mu-$ & •, rma & •,OV० & $\cdot, \cdot v \cdot$ & $\cdot, \varepsilon \cdot \varepsilon$ & $r$ \\
\hline •,rar & $\cdot, \cdot \leq \varepsilon-$ & •,01\%- & $\cdot, 119-$ & $\cdot, 11 \varepsilon-$ & $\cdot, \cdot Y \wedge$ & $r$ \\
\hline$\cdot, T \leqslant V$ & $\cdot, \varepsilon \leqslant 1$ & •, ¿१९- & $\cdot, r \wedge \varepsilon$ & •, YMq- & $\cdot, \cdot 0 \mathrm{OV}-$ & $\varepsilon$ \\
\hline •, OrM & $\cdot, \cdot 1 \varepsilon$ & $\cdot, 179-$ & $\cdot, 190-$ & $\cdot, \cdot 19$ & •, ชท & 0 \\
\hline • & -,V0r & •, YצY & $\cdot, \cdot \mathrm{VI}$ & $\cdot, 119-$ & $\cdot, \cdot \mu$. & 9 \\
\hline$\cdot, 711$ & $\cdot, .90$ &., $1 \mathrm{ro}$ & •, V乏१- & $\cdot, 1 \cdot r-$ & $\cdot, 1 Y \varepsilon$ & $\mathrm{v}$ \\
\hline$\cdot, 7 \varepsilon \cdot$ & $\cdot, \cdots 9$ & $\cdot, \mathrm{v} 70$ & $\cdot, \cdot V Y-$ & •, YIV- & $\cdot, \cdot, \varepsilon q-$ & $\wedge$ \\
\hline •, \&rr & $\cdot, \cdot r 0$ & $\cdot, \cdot \leqslant 0$ & $\cdot, \cdot \cdots \varepsilon-$ & •, 1YY- & $\cdot, T \leqslant Y$ & 9 \\
\hline אודף, & •, $\vee \backslash \varepsilon$ & $\cdot, Y \cdot Q-$ & $\cdot, 17 r-$ & •, rre & $\cdot, \cdot, \varepsilon \varepsilon-$ & 1. \\
\hline - & $\cdot, \cdot 94-$ & $\cdot, 1$ ro & $\cdot, r \cdot q$ & •, vo. & $\cdot, 119-$ & 11 \\
\hline$\cdot, \varepsilon r M$ & $\cdot, \cdot 99$ & $\cdot, \cdots Y-$ & $\cdot, \cdot V Y-$ & $\cdot, \cdot \varepsilon \cdot$ & $\cdot, 7 \varepsilon 1-$ & Ir \\
\hline .,OYo &., $1+9$ & $\cdot, \cdot \times 1-$ & $\cdot, \cdot 9 \xi-$ & $\cdot, v \cdot r$ & $\cdot, \cdot \vee \vee \vee-$ & ir \\
\hline \multirow[t]{2}{*}{$V, 1 \varepsilon$. } & $1, \mu \bullet \Lambda$ & 1, r.4 & $1, \varepsilon Y \wedge$ & $1, \varepsilon Y q$ & 1,001 & $*$ \\
\hline & $19, \cdot 19$ & 19,111 & $r \cdot, \cdots$ & $r \cdot, \cdot 1 \varepsilon$ & $r l, \Lambda Y$. & 券絭 \\
\hline \multirow[t]{2}{*}{$0 \varepsilon, 91 \mu$} & $1 \cdot, \leqslant \leqslant 4$ & $1 \cdot, 0 \cdot V$ & $1 \cdot, 9 \wedge \varepsilon$ & 1.,99r & $11,9 \wedge \varepsilon$ & 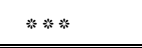 \\
\hline & •, rq々 & $\cdot, r \leqslant q$ & $\cdot, r \cdot q$ & $\cdot, Y V \Lambda$ & $\cdot, r 00$ & 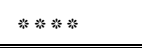 \\
\hline
\end{tabular}

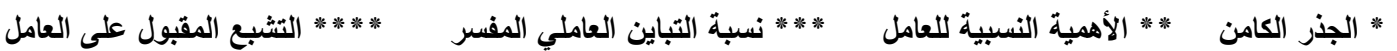
من خـل الجدول (ج ( ) والذي ييين مصفوفة العوامل بعد إجراء التدوير المتعامد تم التوصل إلى (0) عوامل

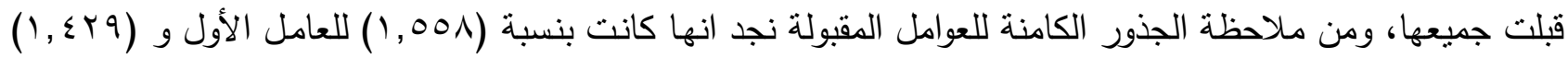

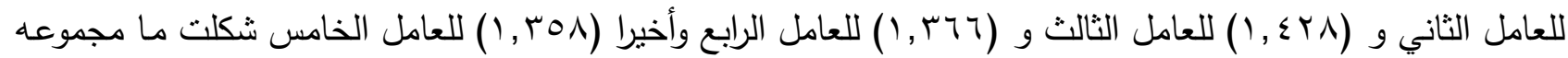

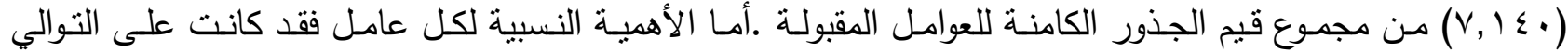

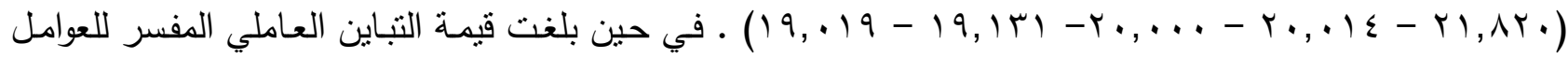

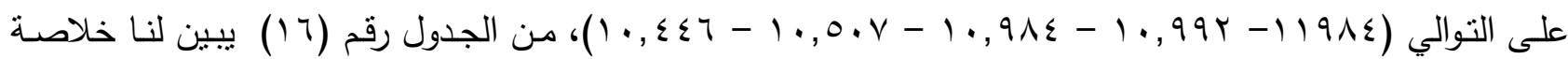
حصول الاختبـارات المعتمدة في التحليل العـاملي على الصدق العـاملي حسب نسب تشبعها المقبول على العوامـل المقبولة وكالاتي: 


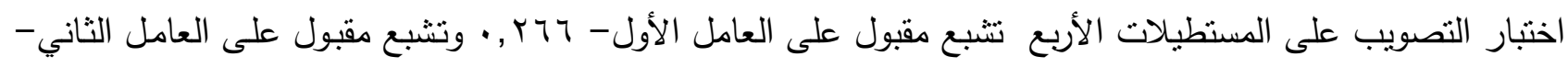

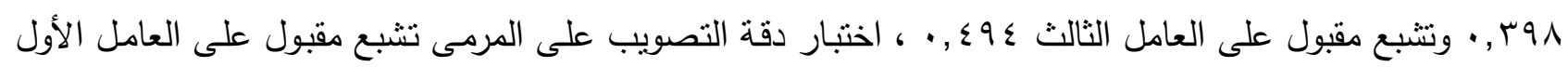

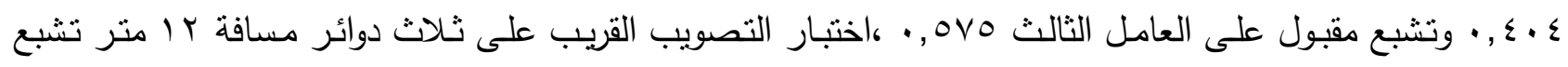

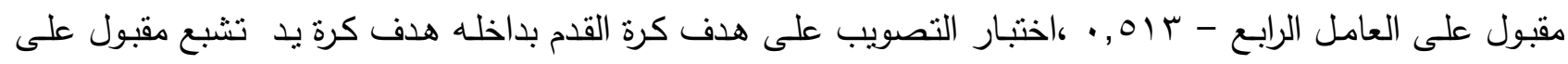

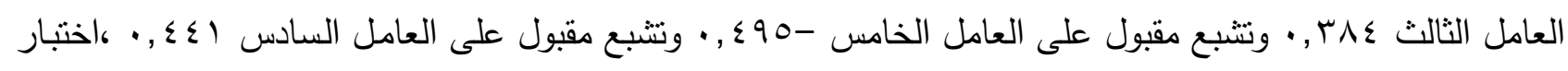

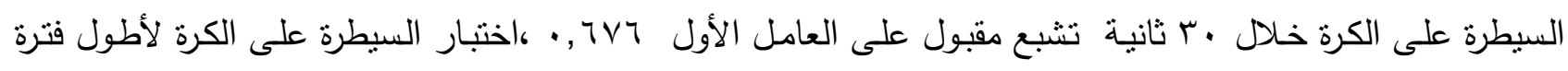

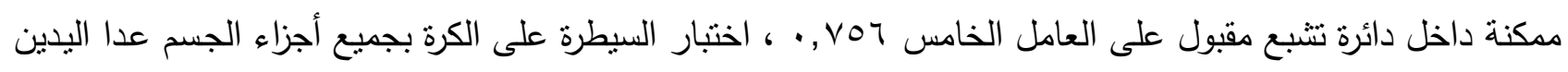

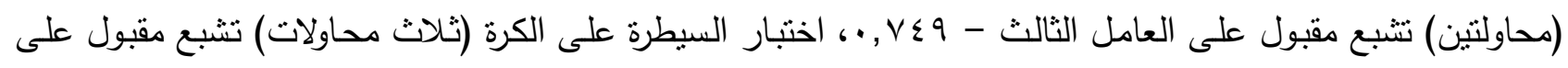

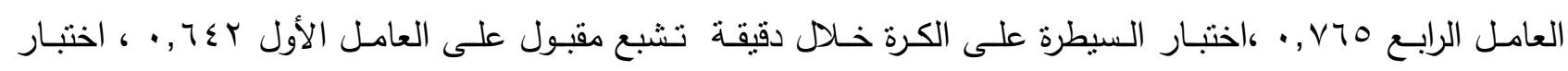

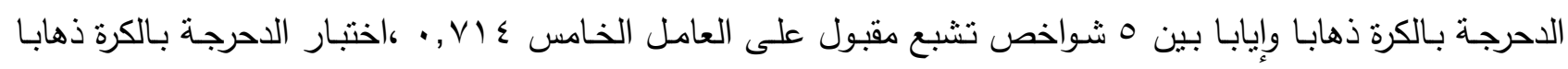

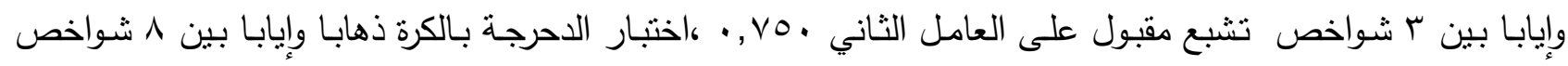

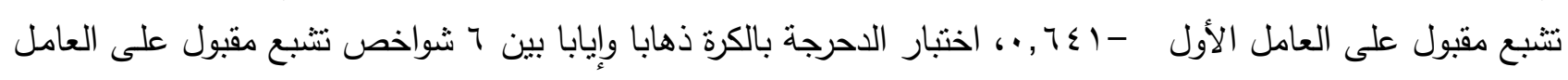

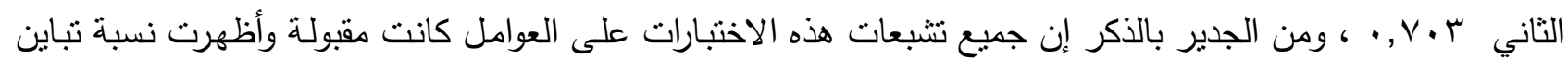

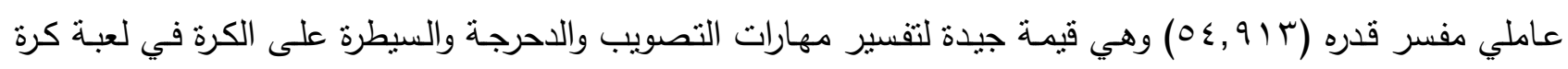

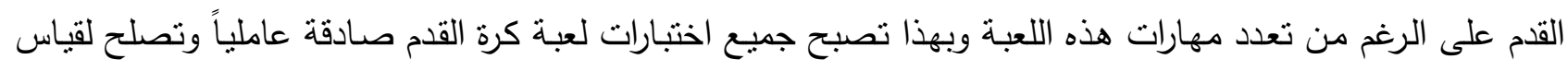

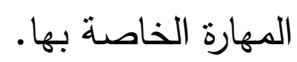

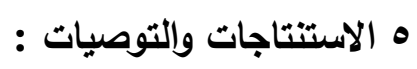
0 - الاستنتاجات : من خلال تحليل الجداول الخاصة بمصفوفة العوامل بعد التدوير للاختبارات المهارية للألعاب تم التوصل إلى الى

الاستتناجات الآتية

ه-1-1 الاستنتاجات الخاصة بلعبة كرة السلة :

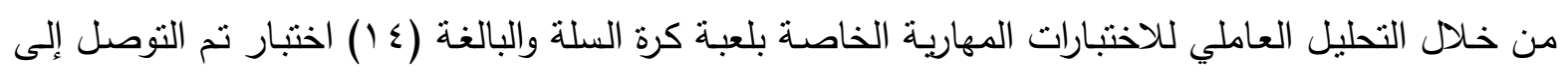

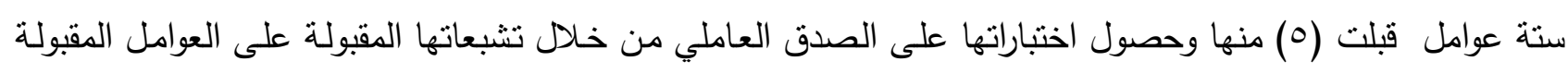

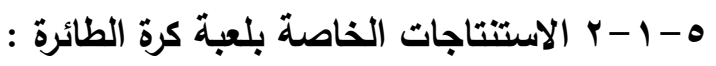

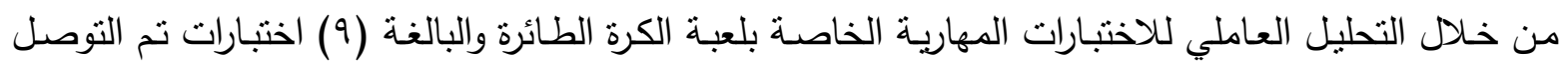

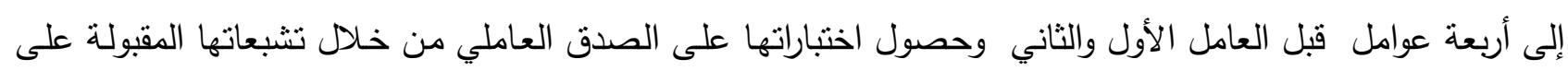
العوامل المقبولة.

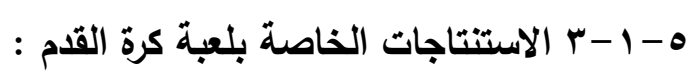

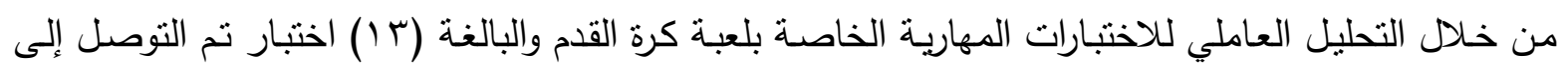

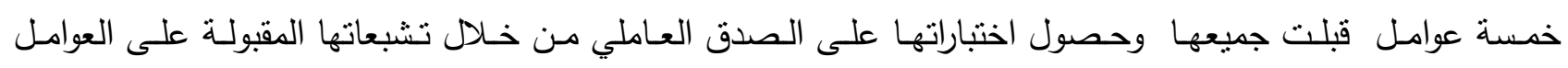




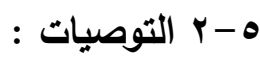

استخدام الاختبارات المهارية الخاصة بألعاب .كرة السلة، كرة الطائرة ، كرة القدم )

المستخلصة من التحليل العاملي كمؤشر للقبول عند اختيار الطلاب المتقدمين إلى كلية التربية الرياضية لتوفر شروط الطيات

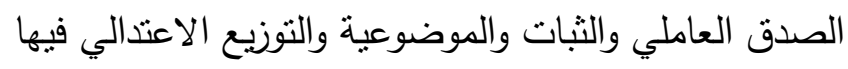

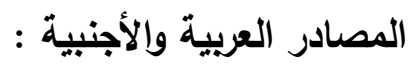

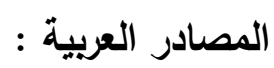

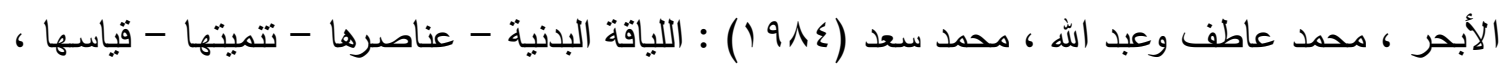

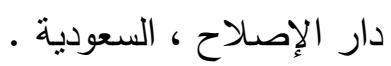

حسانين ، محمد صبحي (979 (1) : القياس والنقويم في التربية الرياضية ، ط1 ، جا، دار الفكر العربي ، القاهرة.

حسانين، محمد صبحي ( r (191 ) : طرق بناء و تقنين الاختبارات والمقاييس في التربية البدنية ( الطرق العاملية ) ، ط ا ه مطابع دار الثعب ، القاهرة .

حسانين ، محمد صبحي (1990) : القياس والثقويم في التربية البننية الرياضية ، جا، طـ ، دار الفكر

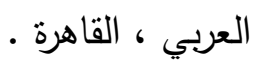

حيدر ، عادل عبد الحليم (1997) : نحليل الصدق لاختبار مشروع اللياقة البدنية لطلاب المرحلة الثانوية ، الثابة

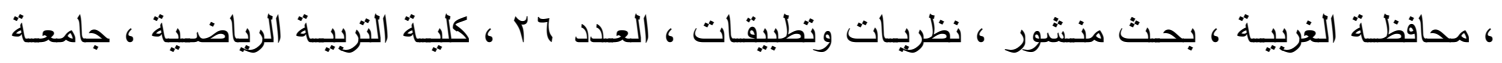
الإسكندرية .

خاطر ، احمد محمد و البيك ، علي فهمي (9V^ (1) : القياس في المجال الرياضي ، مطابع جريدة السفير

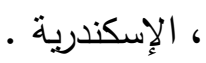

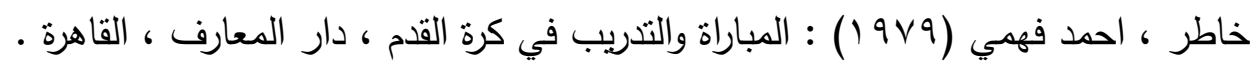

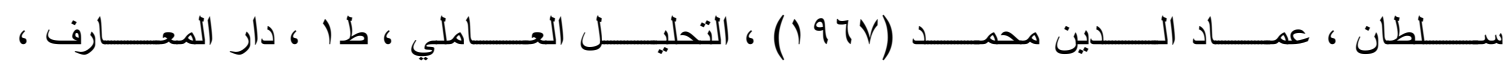
مصر

علاوي ، محمد حسن ورضوان ، محمد نصر الدين (9Av (1) : اختبارات الأداء الحركي ، طץ ، دار الفكر

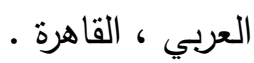

علاوي ، محمد حسن ورضوان ، محمد نصر الدين (911 (1) : القياس في التربية الرياضية وعلم النفس الرياضي ، طن ، دار الفكر العربي ، القاهرة .

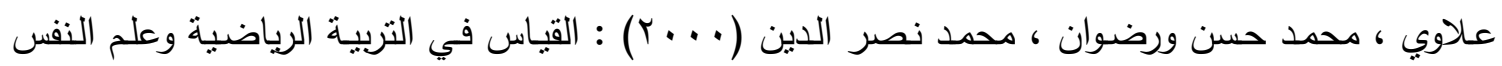
الرياضي ، دار الفكر العربي ، القاهرة . فرج ، صفوت (·911) : التحليل العاملي في العلوم السلوكية ، دار الفكر العربي ، القاهرة .

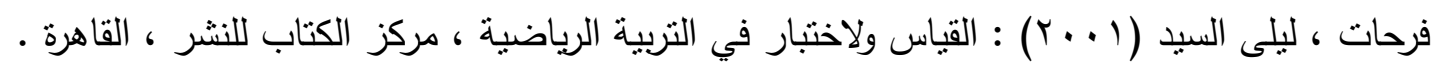

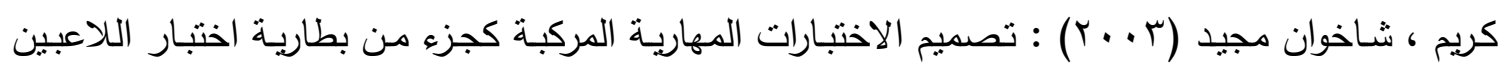
الثباب بكرة القدم في مدينة أربيل ، أطروحة دكتوراه غير منشورة ، جامعة صلاح الديد الدين ،أربيل . 
محمد ، محمد مصدق محمود (99V (19) : بناء بطارية اختبارات المهارات الأساسية في كرة الماء (دراسات

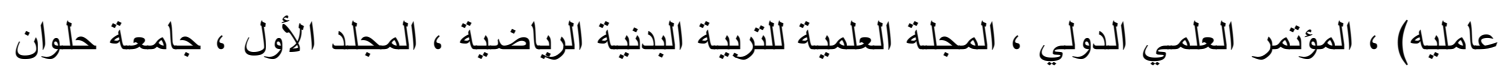

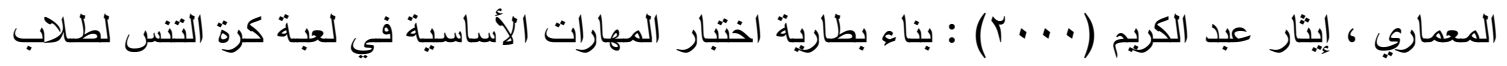

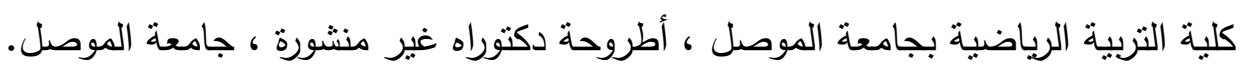
ه الدنسي ، محمود عبد الحليم (919 (19) : الإحصاء والقياس في التربية وعلم النفس ، دار المعرفة الجامعة ،

$$
\text { الإسكندرية . }
$$

- Montys. J. Henry (1978): an Introduction to measurement in physical education,

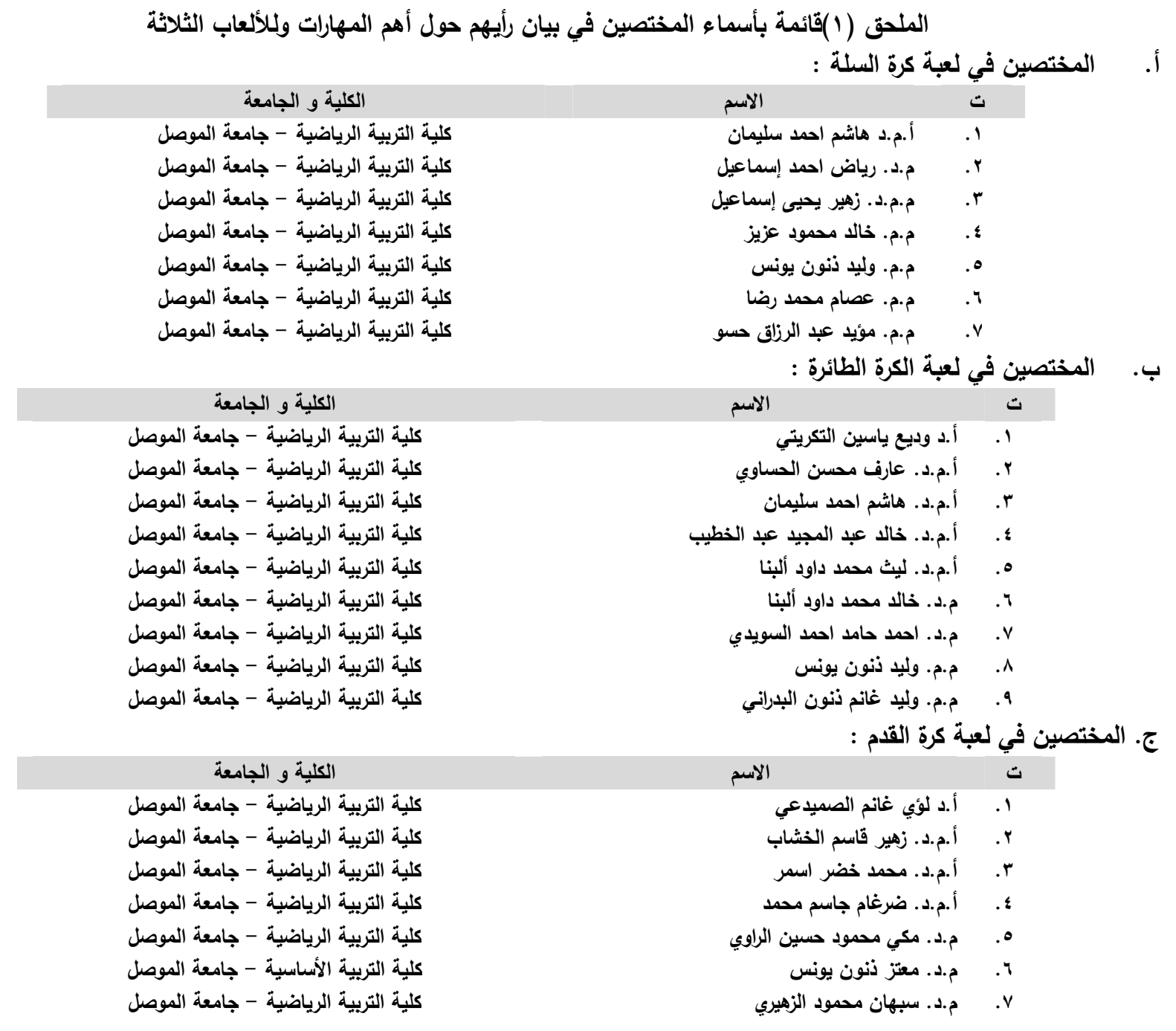

الملحق (ץ) قائمة بأسماء المختصين في بيان رأيهم حول أهم الاختبارات المهارية وللألعاب الثثلاثة

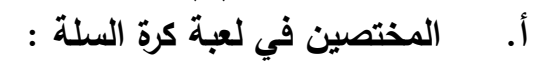

\begin{tabular}{|c|}
\hline الكلية و الجامعة \\
\hline كلية التربية الرياضية - جامعة الموصل \\
\hline كلية التربية الرياضية - جامعة الموصل \\
\hline كلية التربية الرياضية - جامعة الموصل \\
\hline كلية التربية الرياضية - جامعة الموصل \\
\hline
\end{tabular}

\begin{tabular}{|c|c|}
\hline 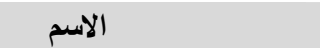 & $ت$ \\
\hline أ.م.د هاشم احمد سليمان & .1 \\
\hline م.د. رياض احمد إسماعيل & $r$ \\
\hline م.م .د. زهير يحيى إسماعيل & \\
\hline م.م. خالد محمود عزيز & \\
\hline
\end{tabular}




$$
\text { كلية كلية التربية الرياضية - جلتربية الرياضية - جامعة الموصلة الموصل }
$$$$
\text { الكلية و الجامعة }
$$

كلية التربية الرياضية - جامعة الموصل

كلية التربية الرياضية - جامعة المباضية - جامعه الموصل

كلية التربية الرياضية - جامعة المباضة - جامعة الموصل

كلية التربية الرياضية - جامعة المبية - جامعة الموصل

كلية التربية الرياضية - جامعة الرياضة - جامعة الموصل

كلية التربية الرياضية - جامعة الرياضة - جامعة الموصل

كلية التربية الرياضية - جامعة الموصله

$$
\text { الكلية و الجامعة }
$$

كلية التربية الرياضية - جامعة الموصل كلية التربية الرياضية - جامعة الموصلة الريلة - جامعة الموصل كلية التربية الرياضية - جامعة المبية الموصل كلية التربية الرياضية - جامعة الموصلة الريلة - جامعة الموصل كلية التربية الرياضية - جامعة الموصل كلية التربية الاساسية - جامعة الموصل الريلة - جامعة الموصل كلية التربية الرياضية - جامعة الموصل

\author{
ه. م.م. وليذ ذنون يونس \\ 7.
}

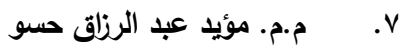

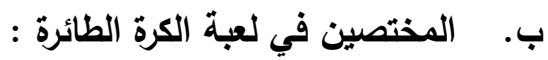

ت الاسم

ا. أ. أ. أد وديع ياسين التكريتي

r. أ. أ.م.د. خالد عبد المجيد عبد الخطيب

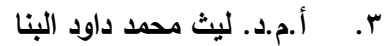

ع. م.د. خالد محمد داود البنا

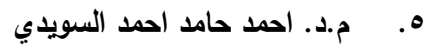

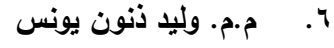

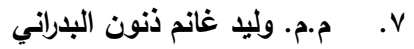

ج. المختصين في لعبة كرة القدم :

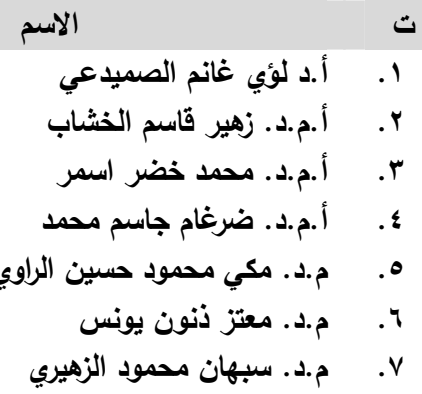

